\title{
Ruthenium Stilbenyl and Diruthenium Distyrylethene Complexes: Aspects of Electron Delocalization and Electrocatalyzed Isomerization of the Z-Isomer
}

\author{
Michael Linseis, ${ }^{\dagger, \$}$ Stanislav Záliš, ${ }^{\S}$ Manfred Zabel, ${ }^{\ddagger}$ and Rainer F. Winter ${ }^{*}{ }^{\dagger}$ \\ ${ }^{\dagger}$ Fachbereich Chemie der Universität Konstanz, Universitätsstraße 31, D 78457 Konstanz, Germany, \\ ${ }^{*}$ Institut für Anorganische Chemie der Universität Regensburg, D 93040 Regensburg, Germany \\ $\S$ J. Heyrovský Institute of Physical Chemistry v.v.i, Academy of Sciences of the Czech Republic, Czech Republic
}

Supporting Information

\begin{abstract}
Regio and stereoselective insertion of the terminal ethynyl functions of 4 ethynylstilbene, the $E$ and $Z$ isomers of 4,4' bis(ethynylphenyl)ethene and a backbone rigidified cyclohexenyl derivative of the $\mathrm{Z}$ isomer into the $\mathrm{Ru}-\mathrm{H}$ bond of the complex $\mathrm{RuClH}(\mathrm{CO})\left(\mathrm{P}^{i} \mathrm{Pr}_{3}\right)_{2}$ provides the corresponding vinyl ruthenium complexes, which have been characterized spectroscopically and by $\mathrm{X}$ ray crystallography. Large red shifts of the UV/vis absorption bands evidence efficient incorporation of the vinyl metal subunit(s) into the

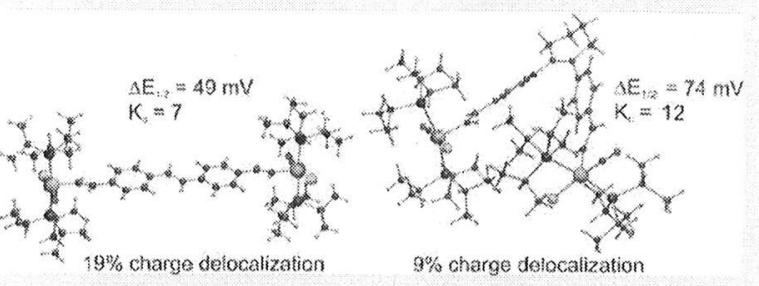
conjugated $\pi$ system. All complexes oxidize at low potentials. The various oxidized forms of all complexes were generated and characterized by UV/vis/NIR, IR and EPR spectroscopies. These studies indicated electrocatalytic $Z \rightarrow E$ isomerization of the oxidized $\mathbf{Z}$ distyrylethene complex $\mathbf{R u} \mathbf{Z} 2$, which is prevented in its backbone rigidified derivative $\mathbf{R u} \mathbf{Z} 2 \mathrm{fix}$. The radical cations of the $E$ and the configurationally stable cyclohexene bridged $Z$ derivatives are spin delocalized on the EPR time scale but charge localized on the faster IR time scale. The degree of ground state charge delocalization in the mixed valent state has been quantified by the incremental shifts of the $\mathrm{Ru}-\mathrm{CO}$ bands upon stepwise oxidation to the radical cations and the dications and was found to be remarkably large $(19 \%$ and $9 \%)$ considering redox splittings $\Delta E_{1 / 2}$ of just 49 or $74 \mathrm{mV}$. Quantum chemical studies with various levels of sophistication reproduce our experimental results including the electronic spectra of the neutral complexes and the intrinsically localized nature of the radical cations of the dinuclear complexes.
\end{abstract}

\begin{abstract}
Introduction
Stilbenes and their more extended, conjugated congeners constitute an extremely important class of compounds with applications e. g. as strong UV absorbers in sunblockers, as two photon absorbing materials ${ }^{1}$ and as molecular conformational switches, ${ }^{2}$ whose switching properties and performances can be altered by metal coordination. ${ }^{3}$ They also constitute an integral part of phenylene vinylene based oligomers and polymers (so called OPVs and PPVs) that become electrically conducting on doping with a suitable oxidant or reductant and thus belong to a class of compounds dubbed as "synthetic metals". 4 Stilbenes are also noted as testing grounds for probing the consequences of structural distortions and oxidation/reduction on their IR and UV/vis spectroscopic properties, ${ }^{5}$ and for experimental and quantum mechanical descriptions of molecular reorganization in the photo or electron transfer triggered $Z / E$ isomer ization. ${ }^{5 \mathrm{~d}, 6}$ Moreover, stilbenyl linkers have recently become popular as bridges spanning terminally appended redox active moieties. ${ }^{7}$ This is done with the hope that their conformation dependent degree of $\pi$ conjugation might allow one to exert control over the electronic coupling between the terminal redox sites in the mixed valent (MV) states.
\end{abstract}

MV systems usually have the design $\left[\mathrm{RA}^{n}\right.$ bridge $\left.\mathrm{RA}^{n+1}\right]$ where redox active end groups RA of the same composition are present in two (formally) different oxidation states, $n$ and $n+1$. Intramolecular electron transfer between $\mathrm{RA}^{n}$ and $\mathrm{RA}^{n+1}$ across the bridge may occur by superexchange, where the bridge provides a pathway for direct coupling of the relevant RA centered valence orbitals, by a hopping mechanism, where the migrating electron or hole intermittently rests on the bridge, or by a combination of both. ${ }^{8}$ Besides these now classical scenarios there are also cases where bridge localized states are energeti cally below the mixed valent one. Examples are radical cations of 9,10 bis(diethynyl)anthracenyl bridged bis(triarylamine) $\mathrm{s}^{8 \mathrm{a}, \mathrm{b}}$ and of arylene bridged bis(ethynyl) ${ }^{9}$ or bis(vinyl) ruthenium complexes, ${ }^{10}$ and mixed ethynyl/vinyl analogues thereof. ${ }^{11}$ While ethynyl and vinyl ruthenium units are rather similar in many respects, vinyl ruthenium entities of the type $-\mathrm{CH}=$ $\mathrm{CH}-\mathrm{RuCl}(\mathrm{CO})\left(\mathrm{PR}_{3}\right)_{2} \mathrm{~L}(\mathrm{~L}=$ neutral two electron donor or free coordination site) are known for their superior conjugation with most organic $\pi$ systems and their strong auxochromic effects. Direct consequences are bathochromic shifts of the $\pi \rightarrow$ 
$\pi^{*}$ absorptions and sizable cathodic shifts of the oxidation and reduction potentials when compared to the parent organic chromophore or electrophore. ${ }^{10 a-f, 12}$ Just like ethynyl ruthenium units such as $\mathrm{X}$ (dppe) ${ }_{2} \mathrm{Ru}-\mathrm{C} \equiv \mathrm{C}-$ or $\mathrm{Cp} *$ (dppe) $\mathrm{Ru}-\mathrm{C} \equiv \mathrm{C}-$, they actively participate in oxidation processes, but without dominating them. ${ }^{10-f, 12 h, i}$ As a consequence, monoxidized radical cation complexes [(Aryl- $\mathrm{CH}=\mathrm{CH}) \mathrm{RuCl}$ $\left.(\mathrm{CO})\left(\mathrm{PR}_{3}\right)_{2} \mathrm{~L}\right]^{\bullet+}$ retain most of the positive charge and of the unpaired spin on the styryl ligand. In addition, the $\mathrm{RuCl}(\mathrm{CO})$ $\left(\mathrm{PR}_{3}\right)_{2} \mathrm{~L}$ tag offers the intense and characteristic $\mathrm{Ru}-\mathrm{CO}$ stretch as an IR label in a spectral region that is unobstructed by most other molecular vibrations. The shift of $\nu(\mathrm{CO})$ upon oxidation is a sensitive probe for the loss of electron density from a metal carbonyl unit and, in mixed valent (MV) diruthenium systems, of the strength of the electronic coupling between them on the vibrational time scale. ${ }^{13}$ This renders an assignment of MV systems to either Class II or Class III within the Robin and Day classification scheme ${ }^{14}$ and the measure ment of ground state delocalization more straightforward and accurate than the usual analysis based on the interpretation of their intervalence charge transfer (IVCT) band(s). The latter procedure frequently suffers from ambiguities in assigning IVCT bands as such or extracting them from overlapping metal to ligand, ligand to metal (MLCT, LMCT), $\pi \rightarrow \pi^{*}$ or ligand field absorptions and from uncertainties about the effective charge transfer distance needed in that analysi s. ${ }^{10 a, c, d, f, 12 i, 15}$ The latter tends to be substantially smaller as the center to center distance between the nominal charge bearing units, particular when the charge is delocalized onto the connecting bridge. ${ }^{\mathrm{d}, 16}$

Here we present an in depth study on vinyl ruthenium complexes derived from differently configured stilbenes including the $E$ and $Z$ isomers and a backbone rigidified $Z$ system where the internal $\mathrm{C}=\mathrm{C}$ double bond is incorporated into a cyclohexenyl ring. The latter induces a markedly higher torsion at the central double bond and avoids complications arising from possible $Z / E$ isomerization. We also include a stilbenyl substituted monoruthenium vinyl complex as a reference system without the added intricacies inherent to the mixed valent character of monoxidized bis(styryl ruthenium) complexes. In making use of the $\mathrm{Ru}-\mathrm{CO}$ tags we arrive at quantitative estimates of ground state delocalization in these extended metal-organic MV systems even though their comproportionation constants $K_{\mathrm{C}}$ are small and no IVCT band is readily identified.

\section{RESULTS AND DISCUSSION}

Synthesis and NMR Characterization. Scheme 1 summarizes the vinyl ruthenium complexes of the present study. They were all prepared from the regio and stereospecific insertion of the $\mathrm{Ru}-\mathrm{H}$ bond of the hydride ruthenium complex $\mathrm{RuClH}(\mathrm{CO})\left(\mathrm{P}^{i} \mathrm{Pr}_{3}\right)_{2}$ into the $-\mathrm{C} \equiv \mathrm{CH}$ bond of the corre sponding terminal alkyne, a reaction usually denoted as hydroruthenation. ${ }^{17}$ This reaction is fast and virtually quantitative and provides the pure complexes after a simple purification step to remove small quantities of the remaining free alkyne. The formation of monometalated byproducts from dialkynes is avoided by slowly adding the respective alkyne to a concentrated solution of the hydride complex. The synthesis of the required alkynes $1 \mathrm{H}, \mathrm{E} 2 \mathrm{H}, \mathrm{Z} 2 \mathrm{H}$ and $\mathrm{Z} 2 \mathrm{fixH}$ as stereochemically pure samples was, however, more tedious and required different strategies for the different isomers. $E 1$ Ethynyl 4 styrylbenzene, $\mathbf{1 H},{ }^{18}$ was prepared in $26 \%$ yield from
Scheme 1

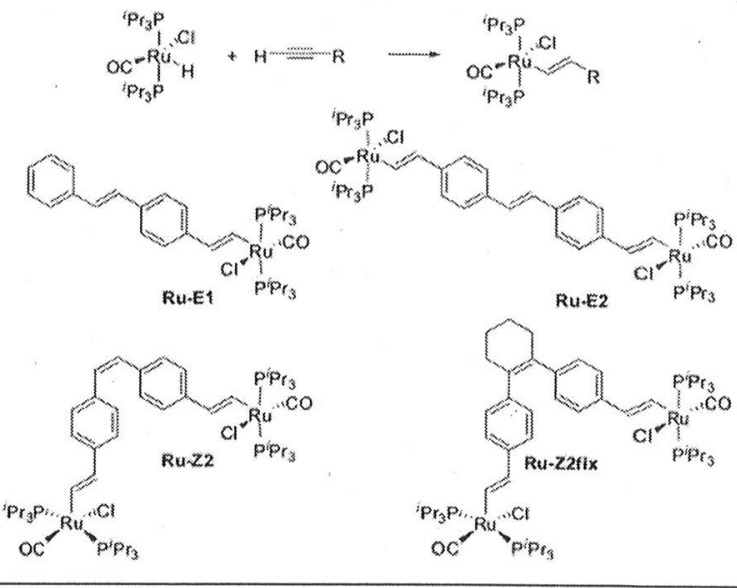

4 ethynylbenzaldehyde and benzylphosphonium bromide via a variation of the Wittig reaction. It was separated from its previously unknown $Z$ isomer (yield $61.9 \%$ ) by chromatog raphy over $\mathrm{SiO}_{2}$. Pure $E 1,2$ bis(4 ethynylphenyl)ethene (E 2H) was obtained from the McMurry coupling of carefully purified 4 ethynylbenzaldehyde (Scheme 2). It is a rare (if not unique) example of the use of an aldehyde bearing an unprotected alkyne function in such reactions. The rather moderate yield of $30.2 \%$ is partly due to the low solubility of the resulting $E$ stilbene which causes considerable losses in the final purification step. Attempts to prepare $\mathrm{E} 2 \mathrm{H}$ via the Sonogashira coupling of $E$ (bis 4 bromophenyl)ethene or $E$ (bis 4 iodophenyl)ethene with TMSA (TMSA $=\mathrm{HC} \equiv \mathrm{C}-$ $\mathrm{SiMe}_{3}$ ) failed in our hands, most probably because of the very low solubility of the halogenated stilbene under the employed reaction conditions. The $Z$ isomer $\mathrm{Z} 2 \mathrm{H}$ was prepared through a reaction sequence involving the Wittig reaction of benzylphosphonium bromide with 4 bromobenzaldehyde (63\% yield), $\mathrm{I} / \mathrm{Br}$ exchange with $\mathrm{BuLi} / \mathrm{I}_{2}$ (88\%), the Sonogashira coupling procedure of Thorand and Krause ${ }^{19}$ (91\%) and, finally, the deprotection of the ethynyl functions (79\%) as outlined in Scheme 3. In passing we note that the Sonogashira coupling of $Z$ bis(4 bromophenyl)ethene with TMSA proceeded with only low conversion and yield and that the present two step procedure via bis(4 iodophenyl) ethene may be superior to the previous route of Babudri et al. ${ }^{20}$ in that it avoids the use of the poorly available 4 iodobenzaldehyde.

The synthesis of 1,2 bis(4 ethynylphenyl)cyclohexene, $\mathrm{Z}$ $2 \mathrm{fixH}$, starts with bromobenzene and adipoylchloride. Double Friedel-Crafts acylation provided 1,6 bis (4 bromophenyl) 1,6 dione in $25 \%$ yield (Scheme 4). Cyclization was effected by intramolecular McMurry reaction $\left(\mathrm{TiCl}_{3}, \mathrm{Cu} / \mathrm{Zn}, \mathrm{DME}\right)$ and furnished 1,2 bis ( 4 bromophenyl)cyclohexene in $36 \%$ yield. Subsequent $\mathrm{I} / \mathrm{Br}$ exchange gave 1,2 bis (4 iodophenyl) cyclohexene (63\%) which successfully underwent Sonogashira coupling with TMSA to give $\mathrm{Z} 2$ fixTMS with a yield of $84 \%$. Deprotection with $\mathrm{KOH} / \mathrm{MeOH} / \mathrm{THF}$ yielded the free dialkyne in $80 \%$ (total yield: $3.8 \%$ over five steps).

All intermediates and alkynes were characterized by ${ }^{1} \mathrm{H}$ and ${ }^{13} \mathrm{C}$ NMR spectroscopy. Details are given in the Experimental Section of the Supporting Information [SI]. Despite the gross overall similarity of the individual spectra, the arene and olefin $\mathrm{CH}$ resonances of the $\mathrm{Z}$ iosmers are generally shifted to higher 
Scheme 2
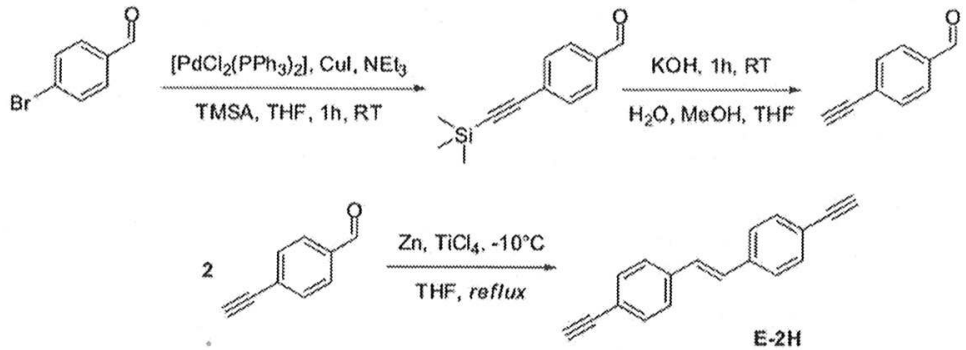

Scheme 3

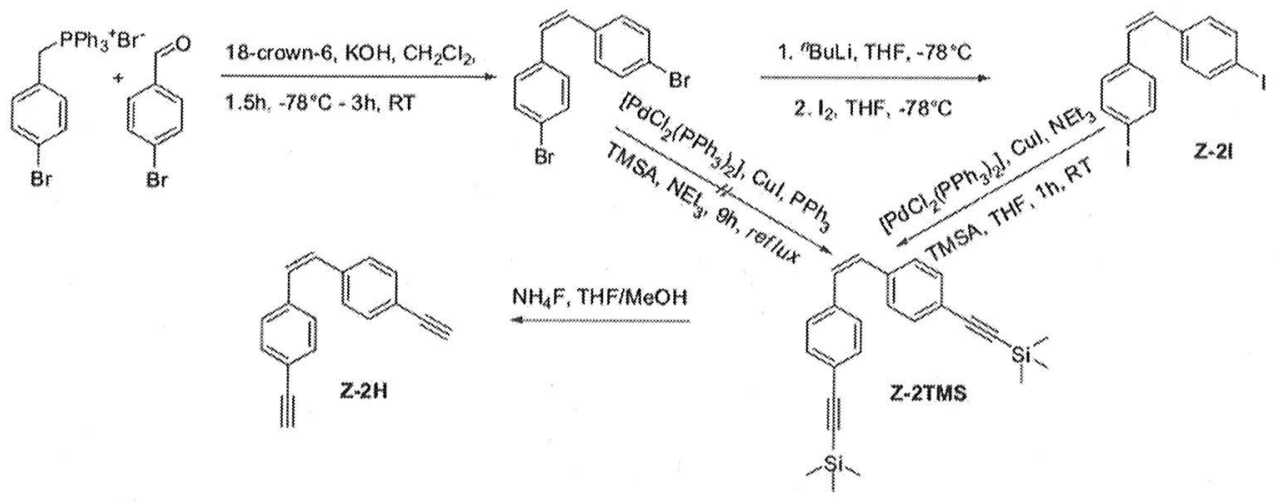

Scheme 4
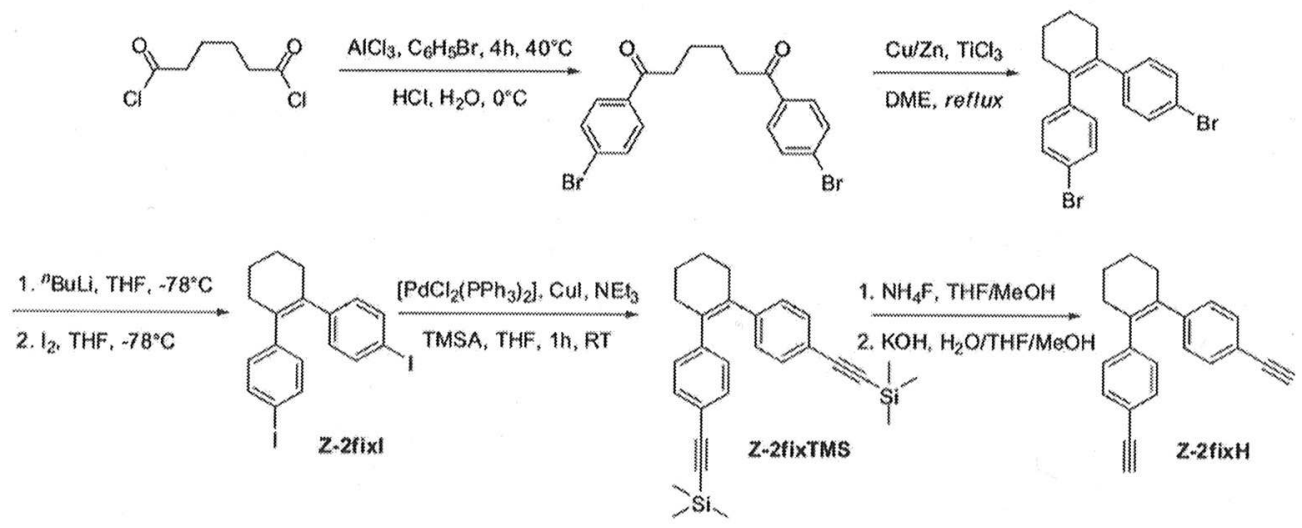

field than in their corresponding $E$ isomers. The olefinic $\mathrm{CH}$ resonances are particularly affected and are thus well suited to check the purity of the samples. Within the series of the differently substituted 1,2 diphenylcyclohexenes, the ipso carbon in 4 position is most sensitive to the nature of the substituent. All alkynes have additional signals near 105 and 95 $\mathrm{ppm}$ for the silyl protected or near 84 and $78 \mathrm{ppm}$ for the free $\mathrm{C} \equiv \mathrm{CH}$ functions.

NMR spectra of the ruthenium complexes show all typical attributes of this class of compounds such as the signals of the vinyl protons and carbon atoms with their characteristic splitting into triplet of doublet or triplet patterns $\left({ }^{3} J_{\mathrm{HH}}=\right.$ $\left.13.4 \mathrm{~Hz},{ }^{3} J_{\mathrm{PH}} \sim 1 \mathrm{~Hz},{ }^{4} J_{\mathrm{PH}} \sim 2 \mathrm{~Hz},{ }^{2} J_{\mathrm{PC}} \sim 11 \mathrm{~Hz},{ }^{3} \mathrm{~J}_{\mathrm{PC}} \sim 3-4 \mathrm{~Hz}\right)$. The vinyl carbon resonances fall in a narrow range at about 150 ppm for the metal bonded and at $135 \mathrm{ppm}$ for the remote carbon atoms. All other expected resonances of the stilbenyl and $\mathrm{P}^{i} \mathrm{Pr}_{3}$ ligands are readily identified and give the correct integral ratios in their ${ }^{1} \mathrm{H}$ NMR spectra. Spectral differences between the $Z$ and $E$ isomers of the stilbenyl bridging ligands are very close to those observed for their organic precursors with the phenylene carbon resonances ortho to the central ethylene bond systematically shifted to lower and those of the neighboring meta carbons shifted to higher field for the $Z$ isomers. Irrespective of the identity of the stilbenyl ligand, the energy of the $\mathrm{Ru}-\mathrm{CO}$ stretch in the IR of $1911 \mathrm{~cm}^{-1}$ and the chemical shift of the phosphane ligands of about $39 \mathrm{ppm}$ in ${ }^{31} \mathrm{P}$ NMR are nearly identical for all complexes.

X-ray Crystallography. Two of the organic precursors and all four complexes of this study were characterized by $\mathrm{X}$ ray crystallography. The results are displayed in Figures 1, 2, and 4-7 while Tables 1 and 2 list the most pertinent structural parameters (for details to the data collection and structure 
Table 1. Selected Structural Parameters of the Stilbenes and Stilbenyl Complexes of This Study and Average Values of Organic Stilbenes $^{a}$

\begin{tabular}{|c|c|c|c|c|c|c|c|c|}
\hline parameter $^{a}$ & $\mathrm{Ru}-\mathrm{El}$ & Ru-E2 & $\mathrm{Ru}-\mathrm{Zz}$ & Ru-Z2fix & $\mathrm{Z2}-\mathrm{Br}$ & Z2-fixH & $\begin{array}{c}E- \\
\text { stilbenes }^{b}\end{array}$ & $Z$-stilbenes ${ }^{c}$ \\
\hline $\mathrm{Ru} \quad \mathrm{C}_{\mathrm{v} 1}$ & $1.994(2)$ & $1.991(4)$ & $1.984(3)$ & $1.993(3)$ & & & & \\
\hline $\mathrm{C}_{\mathrm{v} 1} \quad \mathrm{C}_{\mathrm{v} 2}$ & $1.340(3)$ & $1.332(5)$ & $1.337(5)$ & $1.321(7)$ & & & & \\
\hline $\mathrm{C}_{\mathrm{v} 2} \mathrm{C}_{\mathrm{i1}}$ & $1.471(3)$ & $1.470(6)$ & $1.472(5)$ & $1.476(5)$ & & & & \\
\hline $\mathrm{C}_{\mathrm{il}} \quad \mathrm{C}_{\mathrm{phl}}$ & $\begin{array}{c}1.401(3) \\
1.404(3)\end{array}$ & $\begin{array}{c}1.394(6) \\
1.394(6)\end{array}$ & $\begin{array}{c}1.387(5) \\
1.397(5)\end{array}$ & $1.389(6), 1.399(7)$ & $\begin{array}{c}1.355(7) \\
1.397(8)\end{array}$ & $1.395(4), 1.402(4)$ & & \\
\hline $\mathrm{C}_{\mathrm{ph} 1} \quad \mathrm{C}_{\mathrm{ph} 2}$ & $\begin{array}{c}1.377(3) \\
1.384(3)\end{array}$ & $\begin{array}{c}1.391(6) \\
1.391(6)\end{array}$ & $\begin{array}{c}1.375(5) \\
1.383(6)\end{array}$ & $1.378(6), 1.398(6)$ & $\begin{array}{c}1.385(7) \\
1.380(8)\end{array}$ & $1.374(4), 1.384(4)$ & & \\
\hline $\mathrm{C}_{\mathrm{ph2}} \quad \mathrm{C}_{\mathrm{i} 2}$ & $\begin{array}{l}1.384(3) \\
1.408(3)\end{array}$ & $\begin{array}{c}1.390(6) \\
1.397(7)\end{array}$ & $\begin{array}{c}1.389(5) \\
1.396(6)\end{array}$ & $1.375(6), 1.397(6)$ & $\begin{array}{c}1.421(8) \\
1.396(7)\end{array}$ & $1.398(4), 1.398(4)$ & & \\
\hline$C_{i 2} \quad C_{e}$ & $1.465(3)$ & $1.468(6)$ & $1.469(5)$ & $1.493(4)$ & $1.475(7)$ & $1.485(4)$ & $1.472(17)$ & $1.468(10)$ \\
\hline $\mathrm{C}_{\mathrm{e}} \quad \mathrm{C}_{\mathrm{e}^{\prime}}$ & $1.326(3)$ & $1.330(6)$ & $1.335(5)$ & $1.334(5)$ & $1.333(8)$ & $1.351(4)$ & $1.319(18)$ & $1.32(2)$ \\
\hline $\mathrm{C}_{\mathrm{e}^{\prime}} \quad \mathrm{C}_{\mathrm{i} 2^{\prime}}$ & $1.467(3)$ & $1.468(6)$ & $1.469(5)$ & $1.497(6)$ & $1.485(8)$ & $1.491(4)$ & & \\
\hline $\mathrm{C}_{\mathrm{i} 2^{\prime}} \quad \mathrm{C}_{\mathrm{ph} 2^{\prime}}$ & $\begin{array}{c}1.398(3) \\
1.399(4)\end{array}$ & $\begin{array}{c}1.390(6) \\
1.397(7)\end{array}$ & $\begin{array}{c}1.389(5) \\
1.396(6)\end{array}$ & $1.378(6), 1.394(6)$ & $\begin{array}{c}1.402(7) \\
1.382(8)\end{array}$ & $1.398(4), 1.399(4)$ & & \\
\hline $\mathrm{C}_{\mathrm{ph} 2^{\prime}} \quad \mathrm{C}_{\mathrm{ph1^{ \prime }}}$ & $\begin{array}{c}1.384(3) \\
1.384(4)\end{array}$ & $\begin{array}{c}1.391(6) \\
1.391(6)\end{array}$ & $\begin{array}{c}1.375(5) \\
1.383(6)\end{array}$ & $1.384(7), 1.393(7)$ & $\begin{array}{c}1.387(8) \\
1.378(8)\end{array}$ & $1.379(4), 1.381(5)$ & & \\
\hline $\mathrm{C}_{\mathrm{ph}^{\prime} \mathrm{I}^{\prime}} \mathrm{C}_{\mathrm{il}}$ & $\begin{array}{c}1.385(4) \\
1.375(4)\end{array}$ & $\begin{array}{c}1.394(6) \\
1.394(6)\end{array}$ & $\begin{array}{c}1.387(5) \\
1.397(5)\end{array}$ & $1.385(6), 1.405(6)$ & $\begin{array}{c}1.380(7) \\
1.358(8)\end{array}$ & $1.395(5), 1.406(4)$ & & \\
\hline $\mathrm{C}_{\mathrm{i}^{\prime}} \quad \mathrm{C}_{\mathrm{v} 2^{\prime}}$ & & $1.470(6)$ & $1.472(6)$ & $1.470(6)$ & & & & \\
\hline$C_{v 2^{\prime}} C_{v 1^{\prime}}$ & & $1.332(5)$ & $1.337(5)$ & $1.326(6)$ & & & & \\
\hline $\mathrm{C}_{\mathrm{v} 1^{\prime}} \mathrm{Ru}^{\prime}$ & & $1.991(4)$ & $1.984(3)$ & $1.999(5)$ & & & & \\
\hline$\Phi^{\mathrm{CO}}$ & $16.7(2)$ & $1.5(4)$ & $3.6(4)$ & $11.0(6) / 2.6(5)$ & & & & \\
\hline$\theta^{\prime}$ & $4.97(16)$ & $2.2(3)$ & $0.1(3)$ & $11.1(4) / \quad 10.4(4)$ & & $49.1(3)$ & & \\
\hline$\Phi^{\prime}$ & $11.6(2)$ & $17.8(4)$ & $1.3(4)$ & $17.4(5) / 13.1(5)$ & $22.0(5)$ & & & \\
\hline$\theta$ & $3.3(2)$ & $0.0(5)$ & $5.7(5)$ & $5.6(6)$ & $5.6(6)$ & $7.5(4)$ & $1.2(1.6)$ & $8(3)$ \\
\hline$\Phi$ & $\begin{array}{l}4.8(5) / \\
16.6(2)^{d}\end{array}$ & $6.5(5)$ & $23.7(4)$ & $47.7(4) / 42.7(4)$ & $84.8(5)$ & $55.1(3) / 50.2(3)$ & $7(6)$ & $36(11)$ \\
\hline$\varphi$ & $20.49(11)$ & $0.0(2)$ & $36.5(2)$ & $52.4(2)$ & $89.9(3)$ & $58.36(14)$ & $9(12)$ & $55(3)$ \\
\hline$q / q^{\prime d}$ & $17.2 / 16.1$ & 3.3 & 15.0 & $2.2 / \quad 2.8$ & $10.6 / 28.9$ & $21.1 / 20.6$ & $11(8)$ & $12(29)$ \\
\hline
\end{tabular}

${ }^{a}$ Parameters as defined in Scheme 5 bond lengths in $\AA$, angles in deg. ${ }^{b}$ Average of 160 CSD entries. ${ }^{c}$ Average of 5 CSD entries. ${ }^{d}$ Value of the terminal phenyl ring or the units attached to $\mathrm{Ru}(2)$.

Table 2. Other Bond Parameters Pertinent to the Stilbenyl Ruthenium Complexes

\begin{tabular}{|c|c|c|c|c|}
\hline & $\mathrm{Ru}-\mathrm{E} 1$ & $\mathrm{Ru}-\mathrm{E} 2$ & $\mathrm{Ru}-\mathrm{ZZ}$ & Ru-Z2fix \\
\hline $\mathrm{Ru} \quad \mathrm{Cl}(\AA)$ & $2.4318(6)$ & $2.4465(4)$ & $2.4414(8)$ & $2.4203(17), 2.4353(16)^{a}$ \\
\hline \multirow[t]{2}{*}{$\mathrm{Ru} P(\AA)$} & $2.4184(6)$ & $2.4087(10)$ & $2.4110(10)$ & $2.4037(17), 2.4210(18)$ \\
\hline & $2.4030(6)$ & $2.4109(11)$ & $2.4086(10)$ & $2.4059(16), 2.4016(15)$ \\
\hline Ru C(vinyl) $(\AA)$ & $1.994(2)$ & $1.991(4)$ & $1.984(3)$ & $1.999(3), 1.999(5)$ \\
\hline $\mathrm{Ru} \quad \mathrm{C}(\mathrm{CO})(\AA)$ & $1.810(2)$ & $1.816(4)$ & $1.818(4)$ & $1.796(5), 1.813(6)^{a}$ \\
\hline C O $(\AA)$ & $1.156(3)$ & $1.148(5)$ & $1.147(5)$ & $1.172(6), 1.114(7)^{a}$ \\
\hline P Ru P (deg) & $166.46(2)$ & $173.93(4)$ & $171.13(4)$ & $171.56(4), 165.74(5)$ \\
\hline $\mathrm{Cl} \mathrm{Ru} \quad \mathrm{C}(\mathrm{CO})(\mathrm{deg})$ & $176.53(7)$ & $169.37(13)$ & $171.58(15)$ & $170.22(15), 173.35(17)$ \\
\hline $\mathrm{C}_{\text {vinyl }} \mathrm{Ru} \quad \mathrm{C}(\mathrm{CO})(\mathrm{deg})$ & $88.04(9)$ & $89.42(16)$ & $89.3(2)$ & $89.6(2), 89.3(2)$ \\
\hline$d(\mathrm{Ru})^{b}(\AA)$ & $0.1684(1)$ & $0.1520(3)$ & $0.1625(3)$ & $0.1697(3) / 0.2099(3)$ \\
\hline
\end{tabular}

${ }^{a}$ Values affected by some disorder between the $\mathrm{CO}$ and $\mathrm{Cl}$ ligands. ${ }^{b}$ Displacement of the $\mathrm{Ru}$ atom from the best plane through the basal ligands toward the apical vinyl ligand.

Scheme 5. Definition of the Structural Parameters for the Stilbenes and Stilbenyl Ligands of This Study

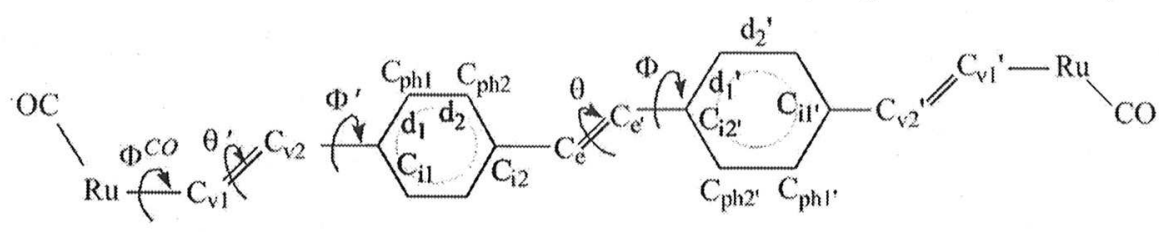

refinement see Tables S1 and S2 of the SI). For discussion of the structural properties of the individual stilbenyl units we adopt the parameters shown in Scheme 5, which are based on the definition of Kochi et al. ${ }^{21}$ According to that definition, $\theta$ denotes the dihedral angle $\mathrm{C}_{\mathrm{ipso}}-\mathrm{C}=\mathrm{C}-\mathrm{C}_{\mathrm{ipso}}\left(\mathrm{C}_{\mathrm{i} 2}-\mathrm{C}_{\mathrm{e}}=\mathrm{C}_{\mathrm{e}^{\prime}}-\right.$ $\mathrm{C}_{\mathrm{i} 2^{\prime}}$ ) and is a measure of the torsion around the central $\mathrm{C}=\mathrm{C}$ double bond, while $\Phi$ symbolizes the average value of the $\mathrm{C}_{\text {ortho }}-\mathrm{C}_{\mathrm{ipso}}-\mathrm{C}=\mathrm{C}\left(\mathrm{C}_{\mathrm{ph} 2}-\mathrm{C}_{\mathrm{i} 2}-\mathrm{C}_{\mathrm{e}}-\mathrm{C}_{\mathrm{e}^{\prime}}\right)$ dihedrals and thus 


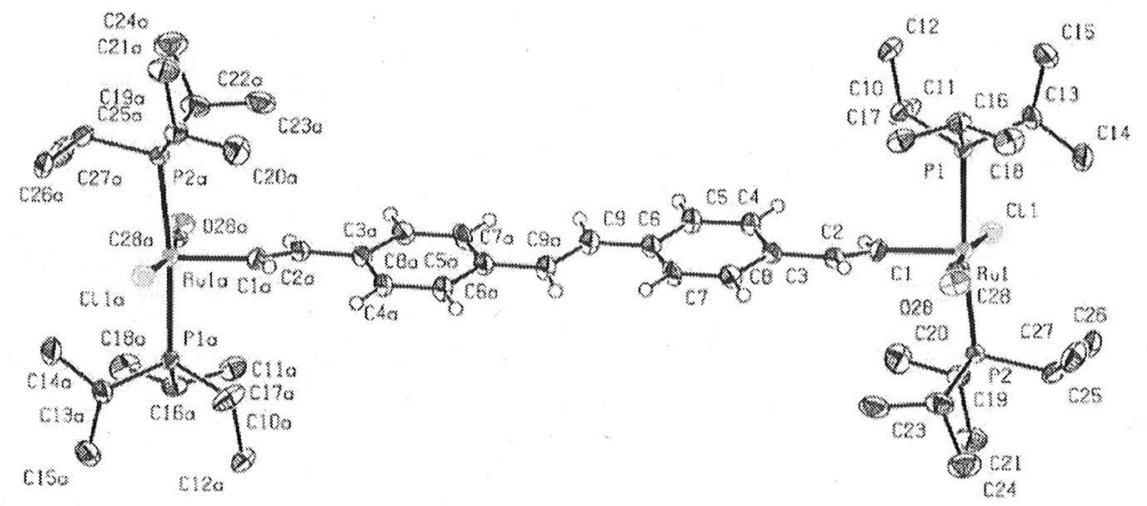

Figure 1. Structure of complex Ru E2 in the crystal. Ellipsoids are drawn at a $50 \%$ probability level. Hydrogen atoms of the $\mathrm{P}^{i} \mathrm{Pr}_{3}$ ligands are not shown.

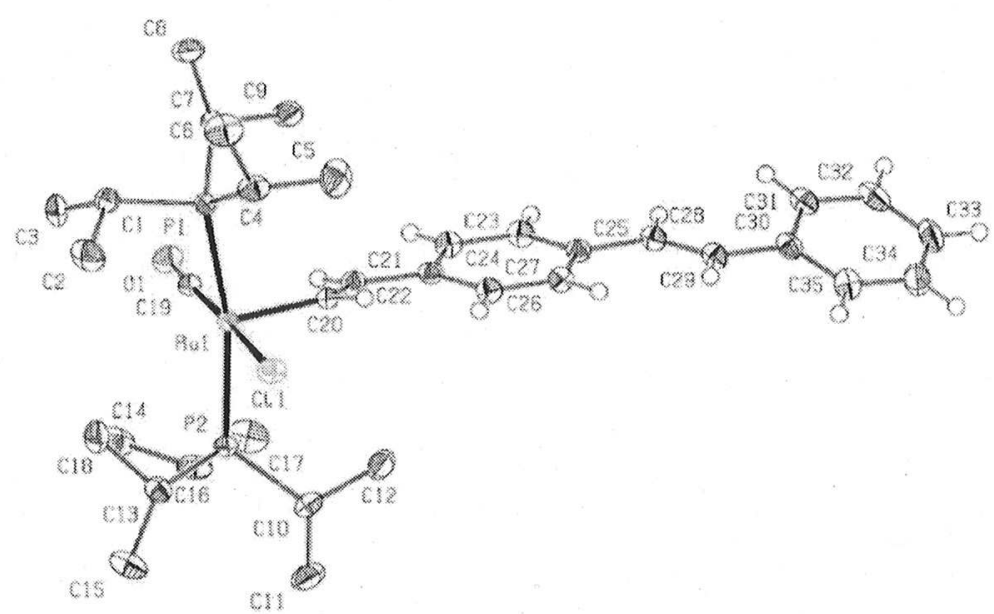

Figure 2. The structure of complex Ru E1 in the crystal. Ellipsoids are drawn at a 50\% probability level. Hydrogen atoms of the $\mathrm{P}^{i} \mathrm{Pr}_{3}$ ligands are omitted for clarity.

measures the deviation of the phenyl ring from coplanarity with the central $\mathrm{C}=\mathrm{C}$ double bond; a negative value denotes counterclockwise rotation. In order to also analyze the metal bonded vinyl groups in this manner we define the equivalent dihedrals $\mathrm{Ru}-\mathrm{C}=\mathrm{C}-\mathrm{C}_{\mathrm{ipso}}$ as $\theta^{\prime}\left(\mathrm{Ru}-\mathrm{C}_{\mathrm{v} 1}=\mathrm{C}_{\mathrm{v} 2}-\mathrm{C}_{\mathrm{i} 1}\right)$, OC$\mathrm{Ru}-\mathrm{C}=\mathrm{C}$ as $\Phi^{\mathrm{CO}}$ and $\mathrm{C}_{\text {ortho }}-\mathrm{C}_{\text {ipso }}-\mathrm{C}=\mathrm{C}$ near the ruthenium atoms $\left(\mathrm{C}_{\mathrm{ph} 1}-\mathrm{C}_{\mathrm{i} 1}-\mathrm{C}_{\mathrm{v} 2}-\mathrm{C}_{\mathrm{v} 1}\right.$, see Scheme 5) as $\Phi^{\prime}$. The quinoidal distortion parameter $q$ is defined as $100 \cdot\left[\left(d_{1}-\right.\right.$ $\left.\left.d_{2}\right) /\left(d^{\prime}{ }_{\mathrm{q} 1}-d^{\prime}{ }_{\mathrm{q} 2}\right)\right]$, where $d_{1}$ is the (average) value of the $\mathrm{C}_{\mathrm{i} 1}-$ $\mathrm{C}_{\mathrm{ph} 1}$ and the $\mathrm{C}_{\mathrm{i} 2}-\mathrm{C}_{\mathrm{ph} 2}$ bond lengths, $d_{2}$ the average of the $\mathrm{C}_{\mathrm{ph} 2}-\mathrm{C}_{\mathrm{ph} 1}$ bond lengths, and $d^{\prime}{ }_{\mathrm{q} 1}$ and $d^{\prime}{ }_{\mathrm{q} 2}$ are the average $\mathrm{C}-\mathrm{C}$ and $\mathrm{C}=\mathrm{C}$ bond lengths in quinomethanes, 1.444 and 1.354 $\AA^{21}$ As an additional parameter we define $\varphi$ as the interplanar angle between the two phenyl rings. Also listed in Table 1 are average values of 160 structurally characterized $E$ and of $5 Z$ stilbenes from the CSD database.

The individual structures are interesting study cases of how the stilbenes adapt to the conflicting demands of maintaining $\pi$ conjugation while avoiding unfavorable steric interactions between the protons of the vinyl $\mathrm{CH}$ and the o phenyl $\mathrm{CH}$ or the $\mathrm{CH}_{2}$ protons of the cyclohexenyl ring and of establishing intermolecular interactions that guide their packing in the crystal. One should note here that the overlap between the $\pi$. orbitals of the ethylenic bond and those of the attached phenyl rings scales with $\cos \Phi$. Loss of conjugation is therefore only moderate even at torsion angles of $20^{\circ}$. This allows the systems considerable conformational freedom.

The structures of Ru E1, Ru E2, Ru Z2, and Ru Z2fix display all characteristic features of five coordinated ruthenium vinyl complexes of the $\mathrm{Ru}(\mathrm{CO}) \mathrm{Cl}\left(\mathrm{P}^{i} \mathrm{Pr}_{3}\right)_{2}$ moiety, i.e. a distorted square pyramidal coordination of the metal ion with $\mathrm{Ru}-\mathrm{C}$ (vinyl), $\mathrm{Ru}-\mathrm{C}(\mathrm{CO}), \mathrm{Ru}-\mathrm{P}$, and $\mathrm{Ru}-\mathrm{Cl}$ bond lengths of about 1.99, 1.81, 2.41, and $2.44 \AA$. These are unexceptional when compared to previous structures of that entity $(d(\mathrm{Ru}-$ $\mathrm{C}($ vinyl): $1.973-2.007 \AA, d(\mathrm{Ru}-\mathrm{C}(\mathrm{CO}))$ : range $1.797-1.830$ $\AA, d(\mathrm{Ru}-\mathrm{P})$ : range $2.387-2.414 \AA, d(\mathrm{Ru}-\mathrm{Cl})$ : range $2.432-$ $2.471 \AA) .{ }^{10 e, 11 b, 12 h, 15 b, 22}$ As usual, the ruthenium atoms are displaced by $\sim 0.16 \AA$ out of the plane of the basal ligand donor atoms toward the apical vinyl ligand, while the basal ligands bend toward the empty coordination site such that the $\mathrm{P}-\mathrm{Ru}-$ $\mathrm{P}$ and $\mathrm{Cl}-\mathrm{Ru}-\mathrm{C}(\mathrm{CO})$ angles are consistently smaller than $180^{\circ}$.

Molecules of Ru E2 are centrosymmetric and show no torsion around the central $\mathrm{C}=\mathrm{C}$ double bond $\left(\theta=0.0(5)^{\circ}\right)$ (Figure 1). The two phenyl rings are strictly coplanar but tilted somewhat against the $\mathrm{C}_{\mathrm{i} 2}-\mathrm{C}_{\mathrm{e}}-\mathrm{C}_{\mathrm{e}^{\prime}}-\mathrm{C}_{\mathrm{i} 2^{\prime}}$ plane as shown by the dihedral angle $\Phi$ of $-6.5(5)^{\circ}$. These structural parameters are very similar to those of parent $E$ stilbene, where, depending on 
the crystal and experiment conditions, $\Phi$ values of 0.0 to $6.8^{\circ}$ have been observed. ${ }^{23}$ Small $\theta^{\prime}$ and $\Phi^{\mathrm{CO}}$ values of $-2.2(3)$ and $1.5(4)^{\circ}$ attest to the small torsion around the vinyl ruthenium bond and the near coplanarity of that bond to the $\mathrm{Ru}-\mathrm{CO}$ vector. The latter has been traced to secondary stabilizing interactions between the filled $\pi$ orbitals of the electron rich vinyl and the empty $\pi^{*}$ orbitals of the CO ligand. ${ }^{24}$ The ruthenium vinyl group is, however, rotated by $-17.8^{\circ}$ with respect to the plane of the attached phenyl ring. Such rotation might be due to packing forces as will be discussed below.

The stilbenyl unit of the complex Ru El shows somewhat larger distortions from an ideal $E$ stilbene structure than dinuclear Ru E2 (Figure 2). While rotation of the phenyl plane at the metal bonded terminus with respect to the central and the terminal ethylene planes of $4.8(5)^{\circ}(\Phi)$ or $11.6(2)^{\circ}\left(\Phi^{\prime}\right)$ is somewhat smaller than in Ru E2, all other torsional parameters are larger with particularly strong rotations of the phenyl ring planes with respect to each other $\left(\varphi=20.5(1)^{\circ}\right)$ and of the terminal phenyl ring with respect to the stilbenyl $\mathrm{C}=\mathrm{C}$ bond $\left(\Phi=16.6(2)^{\circ}\right)$. Torsions of the phenyl rings may originate from steric repulsion between the ethylenic $\mathrm{CH}$ protons and the ortho protons of the attached phenyl ring. Inspection of the repulsive $\mathrm{CH} \cdots \mathrm{HC}$ contacts shows, however, only small differences for the two phenyl rings. In fact, the smallest such contact is observed for the terminal ring of Ru E1 with the larger deviation from coplanarity with the olefinic bond $(d \mathrm{CH} \cdots \mathrm{HC}=2.167 \AA$ vs $2.219 \AA$ for the other $)$. It is thus likely that the observed torsions are more due to the molecule packing than to intramolecular forces.

Ru E2 crystallizes with four $\mathrm{CD}_{2} \mathrm{Cl}_{2}$ solvent molecules per complex unit. Two of these are ordered and connect individual molecules via $\mathrm{Ru}-\mathrm{Cl} \cdots \mathrm{DCCl}_{2} \mathrm{D} \cdots \mathrm{Cl}-\mathrm{Ru}$ hydrogen bonds of 2.710 and $2.747 \AA$ to infinite stepped chains that run along a diagonal of the unit cell (see Figure 3). These stepped chains associate to a brick wall arrangement where a $\mathrm{P}^{i} \mathrm{Pr}_{3}$ ligand of each metal terminus of one molecule interlocks with the voids near the stilbenyl ligand of a complex molecule belonging to the neighboring chains above or below. Additional weak intermolecular contacts are established through $\mathrm{CH} \cdots \pi$ interactions between ${ }^{i} \operatorname{Pr}$ protons and arene carbon atoms, and, even more indirectly, via ${ }^{i} \mathrm{PrCH} \cdots \mathrm{Cl}_{2} \mathrm{CD}_{2} \cdots \pi$ interactions involving the disordered $\mathrm{CD}_{2} \mathrm{Cl}_{2}$ molecules. These latter contacts profit from the torsion of the vinyl ruthenium moiety with respect to the phenyl plane.

Ru E1 crystallizes without a cosolvent. The most important intermolecular interactions are $\mathrm{Ru}-\mathrm{Cl} \cdots \mathrm{H}-\mathrm{C}$ hydrogen bonds of $2.806 \AA$ involving the vinylic proton next to the terminal styryl ring. The so associated molecules are tilted by $43.57(10)^{\circ}$

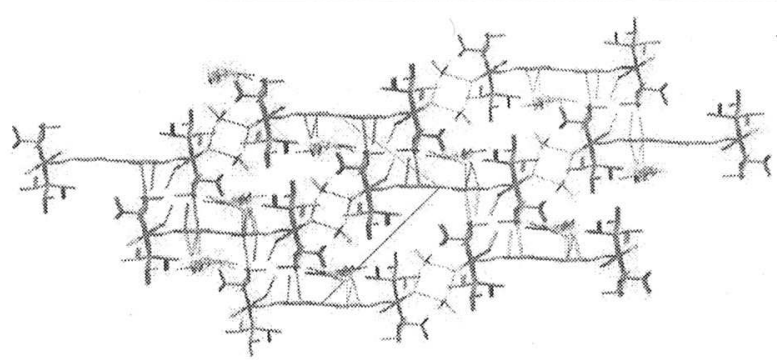

Figure 3. Packing of the stepped $\mathrm{CD}_{2} \mathrm{Cl}_{2}$ connected chains of complex molecules Ru E2 into a brick wall type arrangement. Short intermolecular contacts are indicated by dotted gray lines. when measured by the angle between the metal bonded styryl rings. As may be seen from Figure S1 of the SI, the tilt of the terminal phenyl ring with respect to the ethylene plane generates space in the vicinity of the vinylic proton to facilitate this interaction. Other, weaker contacts exist between the carbonyl oxygen and phenyl carbon atoms C23, C27 and C32 to ${ }^{i} \operatorname{Pr}$ protons of neighboring molecules.

Molecules of $\mathbf{Z 2} \mathbf{B r}$ structurally follow the usual pattern of $Z$ stilbenes in that one phenyl ring maintains rough coplanarity to the ethylene plane while the other one tilts away in order to avoid repulsive interactions between the ortho protons of the phenyl rings. This is seen here in the strongly differing values of the $\mathrm{C}_{\text {ortho }}-\mathrm{C}_{i p s o}-\mathrm{C}=\mathrm{C}$ dihedrals $\Phi$ and $\Phi^{\prime}$ of $-84.8(5)$ and $22.0(5)^{\circ}$. This rotation places the two phenyl rings in a near orthogonal orientation (Figure 4). While a rotation by $22^{\circ}$ maintains more than $90 \%$ of the maximum $\pi$ conjugation, the $85^{\circ}$ tilt signals its nearly complete loss. With $\theta=5.6(6)^{\circ}$ the torsion of the central $\mathrm{C}=\mathrm{C}$ double bond is, however, still small. Individual molecules of $\mathbf{Z 2 ~} \mathrm{Br}$ associate via edge to face $\mathrm{C}-\mathrm{Br} \cdots \pi$ and $\mathrm{C}-\mathrm{H} \cdots \pi$ interactions to right handed helical chains that run along the $b$ axis of the unit cell (see Figure $\mathrm{S} 2$ of the SI). The pitch of each helix corresponds to the length of the $b$ vector. Neighboring helices are interconnected along the $a$ axis via weak $\mathrm{H} 5 \cdots \mathrm{C} 1$ contacts of $2.80 \AA$.

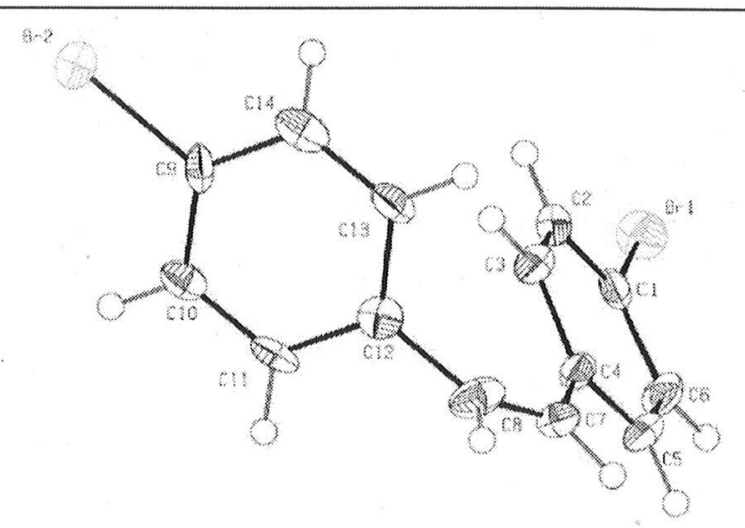

Figure 4. Structure of $\mathbf{Z 2 ~} \mathbf{B r}$ in the crystal. Ellipsoids are drawn at a $50 \%$ probability level.

The structure of centrosymmetric molecules of $\mathbf{R u} \mathbf{Z 2}$ (Figure 5) differs from that of the bromo compound $\mathrm{Z2} \mathbf{B r}$ in that both phenyl rings attain some degree of coplanarity with the central $\mathrm{C}=\mathrm{C}$ double bond. This can be seen from the rather small $\theta$ and $\varphi$ values of -23.7 and $36.5^{\circ}$. Structural parameters describing the torsion around the vinyl ruthenium bond are even smaller and attest to near perfect coplanarity of the $\mathrm{Ru}-\mathrm{CO}$ vector, the metal bonded vinyl unit and the attached phenyl ring. All this signals a high degree of $\pi$ conjugation within the entire $\mathrm{Ru}$ bridge $\mathrm{Ru}$ array despite the $Z$ configuration at the central double bond. Unfavorable steric interactions between the ortho protons are alleviated by a slight opening of the $\mathrm{C}_{\mathrm{ph}}-\mathrm{C}=\mathrm{C}$ angle to $132.6(4)^{\circ}$. This angle is somewhat more obtuse than the values in $\mathrm{Z2} \mathrm{Br}$ (129.7(5) and $\left.130.2(5)^{\circ}\right)$ and the average value of other $Z$ configured diphenylethenes $\left(129: 6 \pm 1.6^{\circ}\right)$, including $Z$ diphenylethene $\left(129.5(7)^{\circ}\right)$. Bond angles $\mathrm{C}_{\mathrm{ph}}-\mathrm{C}=\mathrm{C}$ are consistently smaller for $E$ diphenylethene, ${ }^{23} \mathbf{R u ~ E 2}$ and Ru E1, where values of $127.7(1)^{\circ}$, of $127.1(5)^{\circ}$ and $127.8(2)$ and $125.8(2)^{\circ}$ have been observed. 


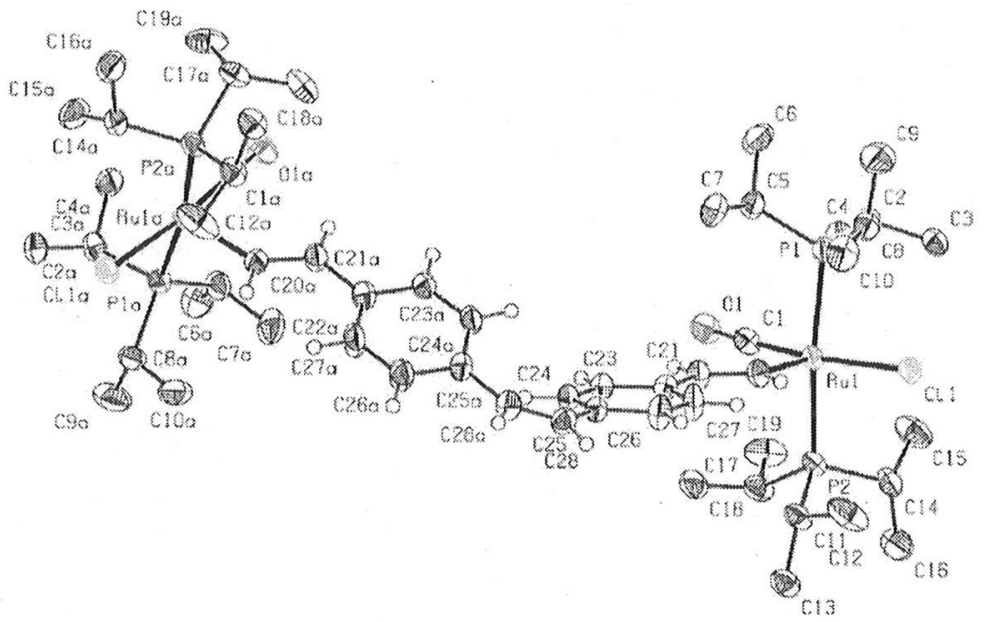

Figure 5. The structure of complex Ru Z2 in the crystal. Ellipsoids are drawn at a 50\% probability level. Hydrogen atoms of the $\mathrm{P}^{i} \mathrm{Pr}_{3}$ ligands are omitted for clarity.

This overall similarity between $\mathbf{R u} \mathbf{Z 2}$ and $\mathbf{R u} \mathbf{E 2}$ also pertains to the packing in the crystal. In the obtained bis(dichloromethane)/tetrakis(methanol) solvate, individual molecules of $\mathbf{R u} \mathbf{Z 2}$ are interconnected via two $\mathrm{Ru}-$ $\mathrm{Cl} \cdots \mathrm{HCCl}_{2} \mathrm{H} \cdots \mathrm{Cl}-\mathrm{Ru}$ bridges of 2.728 and $2.833 \AA$ to infinite one dimensional chains along the diagonal of the $a c$ plane. Within these chains, the diphenylethene bridges of neighboring molecules point alternatingly to opposite sides. Individual chains are interconnected via $\mathrm{CH} \cdots \mathrm{O}$ hydrogen bonds involving the methanol cosolvent molecules ( $\mathrm{d} \mathrm{CH} \cdots \mathrm{O} 2.651$ A) and several contacts between $\mathrm{P}^{i} \mathrm{Pr}_{3}$ protons and arene carbon atoms ranging from 2.75 to $2.77 \AA$, some 14 to $16 \mathrm{pm}$ shorter than the sum of the van der Waals radii (see Figures S3 and S4 of the SI).

Z2 fixH (Figure 6) and Ru Z2fix (Figure 7) constitute a pair of compounds where the central $\mathrm{C}=\mathrm{C}$ double bond is incorporated into a cyclohexenyl ring. Structural studies on cyclohexenyl derived $Z$ stilbenes are rare ${ }^{25}$ with 1,2 diphenyl cyclohexene itself as the closest relative. Both present structures suffer from the presence of two different conformers that differ by the positioning of the two methylene groups opposite the cyclohexenyl double bond. While the structure of $\mathbf{R u} \mathbf{Z 2 f i x}$ could be refined to a $0.587(8) / 0.413(8)$ ratio of the two conformers, this was not possible for $\mathbf{Z 2}$ fixH due to the low amount of the minor conformer. This leads to unrealistically large $\mathrm{C}-\mathrm{C}$ bond lengths within the aliphatic portion of the cyclohexenyl ring. The metric parameters around the $\mathrm{C}=\mathrm{C}$ bond are, however, not affected. The cyclohexenyl ring in $\mathbf{Z 2}$ fixH and Ru Z2fix exhibits its usual half chair conformation. The two conformers differ by the orientation of the $\mathrm{C}-\mathrm{C}$ vector of the methylene groups opposite to the $\mathrm{C}=\mathrm{C}$ bond with respect to the average plane of the other ring atoms (see Figure 8). For free cyclohexene, the coalescence temperature of ring inversion has been determined as $123 \mathrm{~K}^{26}$ In the crystal, the coalescence temperature will most probably be higher such that the conformers are frozen at the temperature of the diffraction experiment of also $123 \mathrm{~K}$. Due to the rapid cooling process, the ratio of the conformers should reflect their relative thermodynamic stabilities. Both conformers cannot adopt an ideal geometry due to steric crowding. In the major conformer A all methylene groups adopt an almost staggered orientation but there are short contacts of 2.07 and $2.15 \AA$ between methylene protons $\mathrm{H}(57 \mathrm{~B})$ and $\mathrm{H}(60 \mathrm{~B})$ to the ortho phenyl protons $\mathrm{H}(56 \mathrm{~A})$ and $\mathrm{H}(24 \mathrm{~A})$. In conformer B such contacts are avoided at the expense of a quasi ecliptic positioning of one $\mathrm{C}-\mathrm{H}$ bond of each methylene group to a $\mathrm{C}-\mathrm{H}$ bond at a ortho carbon atom of the attached phenyl ring.

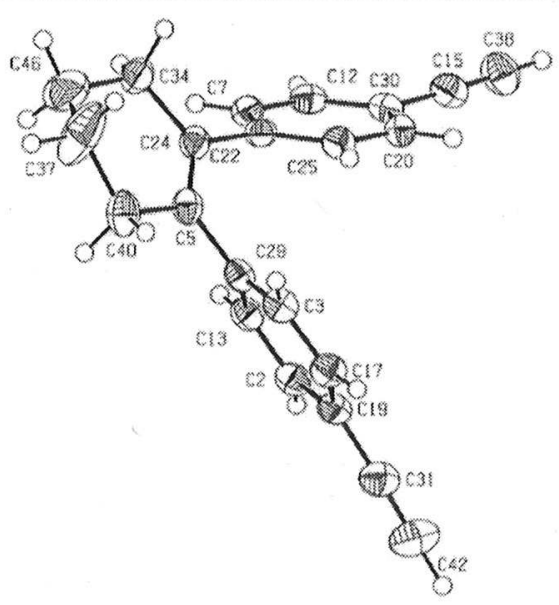

Figure 6. ORTEP of the structure of $\mathrm{Z2} \mathrm{fixH}$ in the crystal. Ellipsoids are drawn at a $50 \%$ probability level.

Incorporation of the ethylenic double bond into a cyclo hexenyl ring causes a drastic loss of conjugation within the stilbenyl part of this structure as is heralded by the large torsional angles $\Phi$ of $-55.1(3)$ and $-50.2(3)^{\circ}$ for $\mathbf{Z 2}$ fixH or 47.7(4) and $42.7(4)^{\circ}$ in $\mathbf{R u ~ Z 2 f i x . ~ I n ~ c o n t r a s t , ~ t h e ~ c e n t r a l ~} \mathrm{C}=$ $\mathrm{C}$ double bond is only slightly twisted as is seen from the $\theta$ angles of $-7.5(4)^{\circ}$ or $5.6(6)^{\circ}$. The previously known structures show values in a similar range $\left(\Phi: 40.4\right.$ to $57.7^{\circ} ; \theta:-6.2$ and $\left.10.0^{\circ}\right) .^{25}$ Ru Z2fix shows the largest torsion of the terminal vinyl groups with respect to the planes of the attached phenyl rings and to the $\mathrm{Ru}-\mathrm{CO}$ vector of all complexes of this study. These torsions help to avoid steric interactions between the $\mathrm{P}^{i} \mathrm{Pr}_{3}$ protons of the neighboring ruthenium moieties which, nevertheless, still remain evident. This is indicated by the rather close approach of carbon atoms C44 and C66 to 3.21(2) $\AA$. 


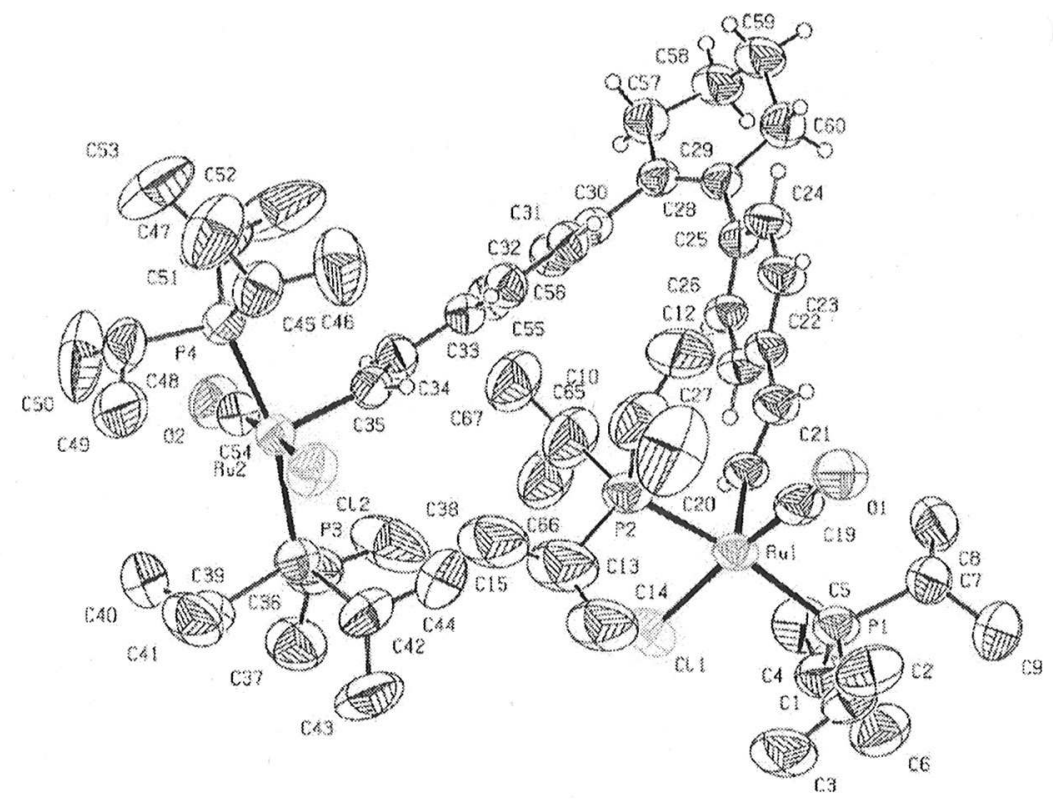

Figure 7. ORTEP of the structure of complex Ru Z2fix in the crystal (major conformer). Ellipsoids are drawn at a $40 \%$ probability level. Hydrogen atoms of the $\mathrm{P}^{i} \mathrm{Pr}_{3}$ ligands and the disorder of two $\mathrm{P}^{\prime} \mathrm{Pr}_{3}$ groups on $\mathrm{P} 2$ are not indicated.
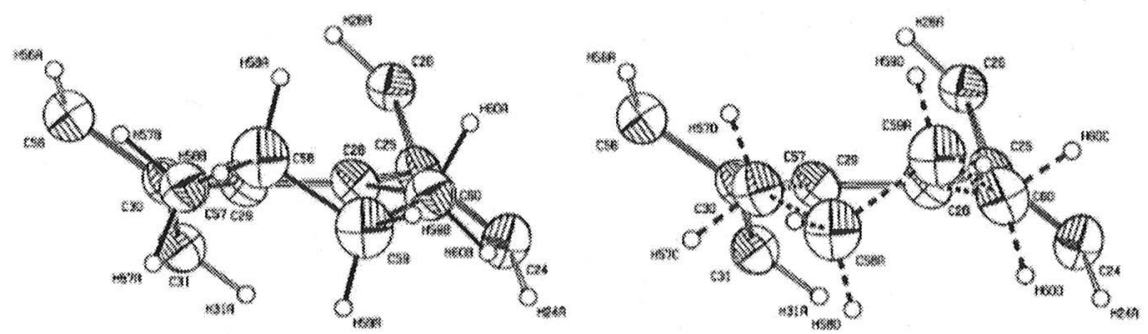

Figure 8. ORTEP showing the two different conformers within the crystal of Ru Z2fix; left: major conformer A, right: minor conformer B.

In the absence of cosolvent in the unit cell of Ru Z2fix the chloride ligands form only weak $\mathrm{Ru}-\mathrm{Cl} \cdots \mathrm{H}-\mathrm{C}$ contacts of $2.866 \AA$ with ${ }^{i} \operatorname{Pr}$ proton $\mathrm{H}(41)$ of a neighbor molecule in such a way that one chloride ligand of each molecule contacts a proton of its partner. The box shaped "dimers" thus formed are then interlinked by several $\mathrm{C}-\mathrm{H} \cdot \mathrm{\cdots} \mathrm{C}$ contacts involving various ${ }^{i} \mathrm{Pr}_{\mathrm{CH}}$ protons and carbon atoms of the phenyl rings. These contacts are 0.1 to $0.2 \AA$ shorter than the sum of the VdW radii (see Figure S5 of the SI for details).

DFT calculations complexes with $\mathrm{P}^{i} \mathrm{Pr}_{3}$ ligands replaced by $\mathrm{PMe}_{3}$ as models for the experimental systems Ru E1, Ru E2, Ru Z2 and Ru Z2fix (denoted as Ru E1 ${ }^{\mathrm{Me}}$, Ru E2 $2^{\mathrm{Me}}$, Ru Z2 $2^{\mathrm{Me}}$ and Ru Z2fix ${ }^{\mathrm{Me}}$ ) were performed (for details see the Experimental Information). As shown by the comparison in Table S3 of SI, they match the structural parameters of the real complexes well. Bond lengths are reproduced within $0.02 \AA$. Somewhat larger deviations are only found for the $\mathrm{Ru}-\mathrm{P}$ distances which are underestimated by $\sim 0.05-0.06 \AA$ due to the replacement of $\mathrm{P}^{\mathrm{i}} \mathrm{Pr}_{3}$ by $\mathrm{PMe}_{3}$ in the model systems. The calculated structures, however, tend to display higher degrees of coplanarity between the individual aryl rings and the central or peripheral ethylenic bonds (dihedrals $\Phi$ and $\Phi^{\prime}$ ) and the Ru$\mathrm{CO}$ units and the peripheral ethylenic bonds (dihedrals $\Phi^{\mathrm{CO}}$ ). Thus, the calculated $\Phi^{\mathrm{CO}}$ of $-1.5^{\circ}$ for $\mathbf{R u}$ El contrasts to the experimental value of $-16.7(2)^{\circ}$. Likewise, the calculated dihedrals $\Phi$ and $\Phi^{\prime}$ averaging at $2.7^{\circ}$ and $7.0^{\circ}$ of $\mathbf{R u ~ E 2}$ are appreciably smaller than those found in the crystal, $-6.5(5)^{\circ}$ and $-17.8(4)^{\circ}$. This supports our notion that conformations of these molecules are influenced by intermolecular interactions in the crystal lattice.

IR and UV/vis spectroscopy. Stilbenes are among those compounds whose IR and UV/vis spectra have been studied with particular scrutiny. This emanates from their pivotal role as constituents of conjugated oligomers and polymers of the phenylene vinylene type and the insight into the symmetry and structure dynamics in the ground and electronically excited states that can be gained from resolved vibronic couplings in their electronic spectra. With increasing level of knowledge and sophistication the focus has continuously shifted to utilizing stilbenes as benchmark systems for novel experimental techniques or as reference systems for evaluating the perform ance of quantum chemical methods. ${ }^{27}$ Detailed experimental ${ }^{28}$ and quantum chemical ${ }^{29}$ studies of the vibrational spectra of $E$ and $Z$ stilbenes provide a solid basis for the assignment of most vibrational bands in the IR and Raman spectra of the present complexes (see Table 3). Representative vibrational spectra of solid crystalline (IR) or powdery (Raman) samples of the isomeric pair of compounds $\mathbf{R u} \mathbf{E 2}$ and $\mathbf{R u} \mathbf{Z 2}$ are displayed in Figure 9. 
Table 3. IR Spectroscopic Data of the Stilbenyl Complexes in Their Various Oxidation States

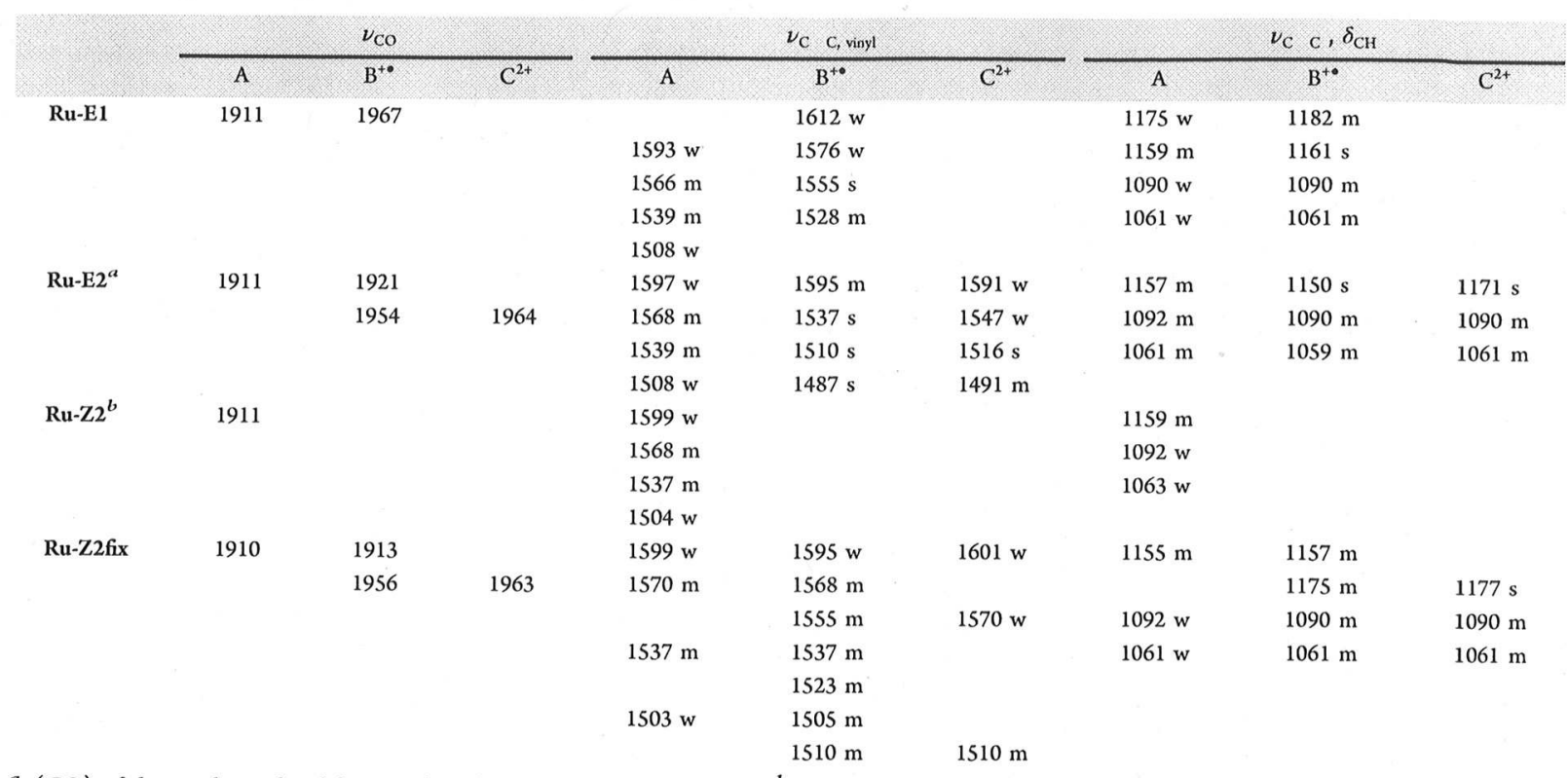

${ }^{a} \nu(\mathrm{CO})$ of the singly oxidized forms values from nonlinear curve fitting. ${ }^{b}$ No data for oxidized forms available due to electrocatalytic isomerization to $\mathrm{Ru} \mathrm{E2} 2^{+/ 2+}$.
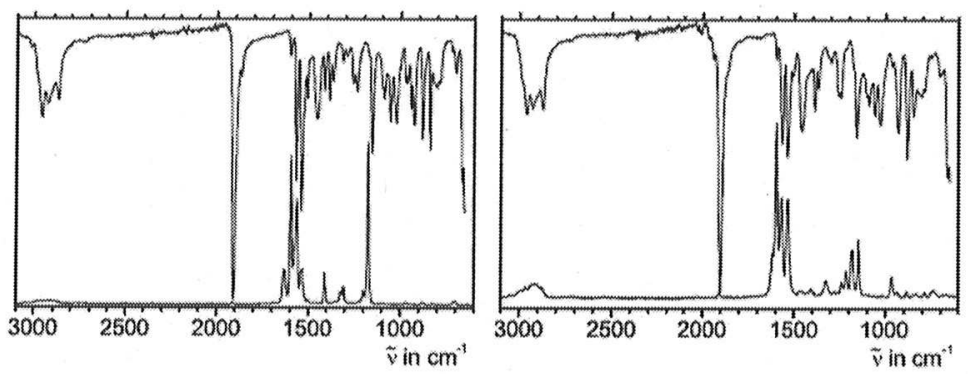

Figure 9. IR (top) and Raman (bottom) spectra of crystalline (IR) or powdered (Raman) samples of Ru E2 (left) and Ru Z2 (right).

The IR spectra are dominated by the intense $\mathrm{Ru}-\mathrm{CO}$ band at 1906 (Ru E2) or $1903(\mathbf{R u ~ Z 2}) \mathrm{cm}^{-1}$. Slight red shifts from their position in DCE solutions (DCE $=1,2$ dichloroethane) might originate from intermolecular interactions in the crystal lattice as they have been detailed in the preceding section. Prominent bands at $1569 / 1540 \mathrm{~cm}^{-1}$ for the $E$ isomer and at $1562 / 1536 \mathrm{~cm}^{-1}$ for the $Z$ isomer are identified as the $A_{1}$ and $B_{2}$ modes of the phenyl rings (the so called quadrant stretches or vibrations $8 \mathrm{a}$ and $8 \mathrm{~b}$ according to the Wilson notification) The moderately intense Raman bands at 1629 and $1596 \mathrm{~cm}^{-1}$ (Ru E2) and at 1617 and $1594 \mathrm{~cm}^{-1}(\mathbf{R u ~ Z 2})$ are assigned to $\nu(\mathrm{C}=\mathrm{C})$ of the inner $\mathrm{C}_{\mathrm{e}}=\mathrm{C}_{\mathrm{e}^{\prime}}$ ethylenic bond and the $A_{1}$ stretching of the phenyl rings and the band at 1564 or 1570 $\mathrm{cm}^{-1}$ to the $\mathrm{B}_{2}$ ring stretch. Both diruthenium complexes have their $\nu\left(\mathrm{C}_{\mathrm{e}}=\mathrm{C}_{\mathrm{e}^{\prime}}\right)$ of the internal $\mathrm{C}=\mathrm{C}$ bond at $\sim 10 \mathrm{~cm}^{-1}$ lower energies than in simple stilbene $(\nu(\mathrm{C}=\mathrm{C})=1639$ or 1629 $\mathrm{cm}^{-1}$ for the $E$ and the $Z$ isomers), ${ }^{29 b}$ which is a consequence of the high mass of the 4 substituent on the attached phenyl rings. The Raman bands at $1524 \mathrm{~cm}^{-1}$ for Ru E2 and at 1535 $\mathrm{cm}^{-1}$ for $\mathbf{R u ~} \mathbf{Z 2}$ do not seem to have equivalents in simple stilbenes and are therefore tentatively assigned as the $\nu(\mathrm{C}=\mathrm{C})$ of the outer $\mathrm{C}_{\mathrm{v} 1}=\mathrm{C}_{\mathrm{v} 2}$. bonds. The lower symmetry of the $Z$ isomer gives rise to a larger number of $\mathrm{C}=\mathrm{C}$ stretching and
$\mathrm{C}-\mathrm{H}$ bending modes in the 1240 to $1180 \mathrm{~cm}^{-1}$ range and causes a strong intensity decrease of the highly intense combination band (CX stretch, $\mathrm{C}-\mathrm{C}$ stretch and antisym metric deformation of the phenyl rings) of Ru E2 at $1178 \mathrm{~cm}^{-1}$ and a red shift to $1146 \mathrm{~cm}^{-1}$. We note that the IR spectrum of $\mathrm{Ru}$ E1, where the central $\mathrm{C}=\mathrm{C}$ double bond binds two different aryl substituents, has a similar band at $1197 \mathrm{~cm}^{-1}$. Raman spectra of Ru Z2 and Ru E2 also feature a weak band for the $\mathrm{Ru}-\mathrm{CO}$ stretch at $1911 \mathrm{~cm}^{-1}$ and thus at the same energy as in solution. This proves that the slightly different values for the crystalline samples are a consequence of intermolecular interactions in the crystal.

Electronic spectra of stilbenes are generally sensitive to configurational and substituent effects. Peak positions red shift as the extension of $\pi$ conjugation within the stilbene chromophore itself and between the stilbene core and unsaturated auxochromic groups increases. The most prom inent feature in the electronic spectra of $E$ stilbenes is a structured, low energy band with a resolved vibrational progression. This so called $\mathrm{A}$ band is assigned to the $1^{1} A_{\mathrm{g}}\left({ }^{1} A\right) \rightarrow 1^{1} B_{\mathrm{u}}\left({ }^{1} B\right)$ transition in $C_{2 h}$ symmetry. The room temperature vibrational progression of $\sim 1340 \mathrm{~cm}^{-1}$ is the result of overlaying overtones and combinations of the Raman active 
symmetrical $\nu(\mathrm{C}=\mathrm{C})$ and $\delta\left(\mathrm{C}_{\mathrm{e}}=\mathrm{C}_{\mathrm{e}}-\mathrm{C}_{\text {ipso }}\right)$ modes and the out of plane $\mathrm{C}_{\mathrm{e}}-\mathrm{C}_{\text {ipso }}$ stretching and torsional modes with additional excitations from excited vibrational states of the electronic ground state (the so called hot bands). ${ }^{27 c, 30}$ In the case of the $Z$ stilbenes, excessive overlay of the $\nu(\mathrm{C}=\mathrm{C})$ mode with a large number of low frequency torsional modes blurs the vibrational progressions into a broad, unstructured absorptio n. ${ }^{30,31}$ The higher energy $B$ band resulting from the $1^{1} A_{u}\left({ }^{1} A\right)$ $\rightarrow 4^{1} \mathrm{~B}_{\mathrm{u}}\left({ }^{1} \mathrm{H}^{+}\right)$transition is often more intense than the $\mathrm{A}$ band and appears at lower energy than in the $E$ isomers. ${ }^{32}$

Such structural and substituent effects are clearly seen for the stilbenyl ruthenium complexes of this study and their alkynyl precursors (see Figure 10 and Figure S6 and Tables S4 and S5

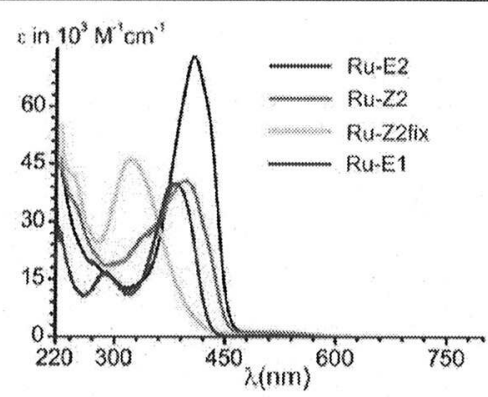

Figure 10. Electronic spectra of the stilbenyl ruthenium complexes.

of the SI). Electronic spectra of alkynes E $1 \mathrm{H}, \mathrm{E} 2 \mathrm{H}, \mathrm{Z} 2 \mathrm{H}$, and $\mathrm{Z} 2$ fixH resemble closely those of other, simpler stilbenes. The $A$ band in the $E$ isomers shows a resolved vibrational progression of $\sim 1400 \mathrm{~cm}^{-1}$. Ethynyl substitution of the $E$ stilbene chromophore causes an incremental red shift of first $2000 \mathrm{~cm}^{-1}$ upon the introduction of the first ethynyl group (E $1 \mathrm{H})$ and then of $1200 \mathrm{~cm}^{-1}(\mathrm{E} 2 \mathrm{H})$ upon introduction of the second one. For the $Z$ configured analogues the $A$ band is much broader and, in the case of $\mathbf{Z 2}$ fixH, only observed as a shoulder on the low energy side of the more intense B Band. As for other $Z$ stilbenes, two main peaks can be extracted with the aid of nonlinear curve fitting. The smaller impact of 2 fold ethynyl substitution on the A band position of $2600 \mathrm{~cm}^{-1}$ for $\mathrm{Z} 2 \mathrm{H}$ and of just $1100 \mathrm{~cm}^{-1}$ for $\mathrm{Z2}$ fixH when compared to their unsubstituted parents ${ }^{25 a, 30 a}$ evidence that the lower degree of conjugation within the stilbene chromophore observed in our crystallographic studies (vide supra) is also maintained in solution. With red shifts of 5700 or $3100 \mathrm{~cm}^{-1}$, the B band appears to be even more sensitive to alkynyl substitution.

(TD) DFT calculations on $\mathrm{PMe}_{3}$ models were undertaken in order to interpret the electronic properties of the mono and diruthenium complexes of this study. A listing of the calculated one electron energies and compositions of selected MOs in the frontier orbital region is provided in Table 4 while graphical representations of these orbitals can be found in Figures S7S10 of the SI. TD DFT calculated electronic spectra (see Figure S11 of the SI) match the experimental ones very well including intensity ratios of intense features in the visible region and aid in their rationalization (see Table S6 of the SI for band assignment). Electronic spectra of the stilbenyl complexes feature a band at $\sim 19600 \mathrm{~cm}^{-1}(510 \mathrm{~nm})$ whose intensity scales with the number of vinyl ruthenium moieties. This band involves excitations from the $d(\mathrm{Ru}) / \pi$ stilbene mixed HOMO (Ru E1) or HOMO/HOMO-1 (Ru E2, Ru Z2, Ru Z2fix) to the essentially metal based LUMO (Ru E1), LUMO+1,
LUMO+2 (Ru E2, Ru Z2fix) or LUMO, LUMO+2 (Ru Z2) While only weakly allowed and little intense, this band is responsible for the brilliant purple red coloration of the styryl ruthenium complexes. The stilbenyl $\mathrm{A}$ band is the most prominent feature of the electronic spectra of every complex and, according to our calculations, involves MOs that are highly delocalized across the entire metal/ $\pi$ ligand chromophores. They are thus assigned to IL $\pi \rightarrow \pi^{*}$ excitations (Table S6 of the SI). Additional coupling to vibrational modes of the $(\mathrm{CH}=$ $\mathrm{CH}-) \mathrm{RuCl}(\mathrm{CO})\left(\mathrm{P}^{\mathrm{i}} \mathrm{Pr}_{3}\right)_{2}$ "substituent" broadens the band to such a degree that even for the $E$ isomers vibrational progression is just faintly discernible. 4 Substitution by one or two vinyl ruthenium moieties red shifts the $\mathrm{A}$ band by 4700 (Ru E1), 6700 (Ru E2), $6500 \mathrm{~cm}^{-1}$ (Ru Z2), or $3800 \mathrm{~cm}^{-1}$ (Ru Z2fix) with respect to their unsubstituted parents. Vinyl ruthenium entities are thus much more powerful auxochromes than simple ethynyl substituents. The effect of vinyl ruthenium substitution is roughly equivalent to that induced by addition of an equivalent number of styryl groups ( $E$ stilbene: $\tilde{\nu}_{\max }=30000$ $\mathrm{cm}^{-1} ; E, E$ 1,4 distyrylbenzene: $\tilde{\nu}_{\max }=25800 \mathrm{~cm}^{-1} ; 4,4^{\prime}$ di $E$ styryl $E$ stilbene: $\left.\tilde{\nu}_{\max }=23700 \mathrm{~cm}^{-1}\right) .^{33}$ The very similar effect on Ru E2 and Ru Z2 indicates that the $Z$ isomer retains its rather small torsion in fluid solution. On the other hand, Ru Z2fix shows an even smaller red shift than Ru E1.

Electrochemistry. All four complexes of this study display deceptively simple voltammograms $\left(\mathrm{CH}_{2} \mathrm{Cl}_{2} / \mathrm{NBu}_{4} \mathrm{PF}_{6}, \mathrm{rt}\right)$ consisting of one chemically reversible and one chemically irreversible wave, both associated with similar peak currents (Figure 11). This matches the wave pattern for alkyl or aryl substituted mononuclear vinyl ruthenium complexes. ${ }^{12 \mathrm{~h}}$ The half wave potential of what appears to be the first wave follows the ordering Ru E2 $\left(E_{1 / 2 \text {, app. }}=0.100 \mathrm{~V}\right) \cong \mathbf{R u ~ Z 2}\left(E_{1 / 2, \text { app }}\right.$. $0.105 \mathrm{~V})<\operatorname{Ru~Z2fix}\left(E_{1 / 2, \text { app. }}=0.164 \mathrm{~V}\right)<\operatorname{Ru}$ E1 $\left(E_{1 / 2}=\right.$ $0.184 \mathrm{~V}$ ), which is readily explained on the basis of the number of vinyl ruthenium donors and the degree of conjugation within the styrene core. Thus, more electron rich dinuclear complexes are easier to oxidize than monoruthenium complex Ru E1, and the less distorted dinuclear complexes derived from the simple $Z / E$ stilbene are easier to oxidize than Ru Z2fix. The half wave potentials are substantially lower as the irreversible peak potentials measured for the parent stilbenes of $\sim 1.10$ and 1.25 $\mathrm{V}^{6 a, b, 34}$ and reflect the strong donor capabilities of the vinyl ruthenium "substituents", clearly surpassing those of the methoxy group $\left(E_{\mathrm{p}} \approx 0.79 \mathrm{~V}\right.$ for $E 1$ methoxy 4 styrylbenze ne, ${ }^{6 \mathrm{~b}} E_{\mathrm{p}} \approx 0.68 \mathrm{~V}$ for $E$ bis(4 methoxyphenyl)ethene) ${ }^{6 \mathrm{~b}, 34}$ and being just slightly inferior to those of the dimethylamino group $\left(E_{1 / 2}=0.04 \mathrm{~V}\right.$ for $E$ bis(4 dimethylaminophenyl)ethene). ${ }^{34}$

A closer look on the CVs reveals, however, some oddities. (i) The oxidation potentials $Z$ styrenes are usually $110-150 \mathrm{mV}$ higher than those of their $E$ isomers, ${ }^{6 \mathrm{~b}}$ while here the first and the second oxidation potentials of $\mathbf{R u} \mathrm{E} 2$ and of $\mathbf{R u ~} \mathbf{Z 2}$ are curiously identical within experimental error. (ii) The diriuthenium complexes exhibit larger peak to peak potential differences and larger half widths of the forward (anodic) peak for the first, chemically reversible couple than expected for a simple Nernstian system and observed for Ru El. Zooming in on the first wave of $\mathbf{R u ~ Z 2 f i x}$, one clearly notes inflections on the cathodic realm of the forward and the anodic realm of the reverse peak (Figure S12, SI). This is suggestive of a wave composed out of two closely spaced, individual one electron waves. In such a scenario, which is usually denoted as an EE process, ${ }^{35}$ the forward peak half widths and peak potential separations are sensitive to the splitting of half wave potentials 
Table 4. DFT G09/PBE0/PCM Calculated One Electron Energies and Compositions of Selected Frontier Molecular Orbitals of the Mono and Dinuclear Model Complexes Ru E1 ${ }^{\mathrm{Me}}, \mathrm{Ru} \mathrm{E2}^{\mathrm{Me}}, \mathrm{Ru} \mathrm{Z2} 2^{\mathrm{Me}}$, and Ru Z2fix ${ }^{\mathrm{Me}}$ Expressed in Terms of Composing Fragments

\begin{tabular}{|c|c|c|c|c|c|c|c|c|c|}
\hline complex & MO & $E(\mathrm{eV})$ & Ru1 & $\mathrm{Vil}^{\prime \prime}$ & $\mathrm{Ph}^{\mathrm{b}}$ & C $\mathrm{C}^{c}$ & Ru2 & $\mathrm{Vi2}^{a}$ & $\mathrm{Ph} 2^{b}$ \\
\hline \multirow[t]{5}{*}{$\mathrm{Ru}-\mathrm{E} 1^{\mathrm{Me}}$} & LUMO+1 & 1.50 & 11 & 9 & 26 & 25 & & & 24 \\
\hline & LUMO & 1.56 & 53 & 12 & 6 & 5 & & & 4 \\
\hline & номо & 5.36 & 19 & 27 & 30 & 12 & & & 9 \\
\hline & Номо 1 & 6.40 & 26 & 9 & 10 & 21 & & & 27 \\
\hline & НОмо 2 & 6.59 & 62 & 4 & 0 & 0 & & & 0 \\
\hline \multirow[t]{9}{*}{$\mathrm{Ru}-\mathrm{E} 2^{\mathrm{Me}}$} & LUMO+2 & 1.41 & 62 & 12 & 2 & 1 & 0 & 0 & 1 \\
\hline & LUMO+1 & 1.45 & 0 & 0 & 0 & 0 & 64 & 12 & 1 \\
\hline & LUMO & 1.56 & 3 & 7 & 27 & 25 & 2 & 8 & 27 \\
\hline & номо & 5.05 & 8 & 13 & 20 & 13 & 8 & 14 & 20 \\
\hline & НОМо 1 & 5.65 & 17 & 18 & 12 & 3 & 16 & 18 & 12 \\
\hline & HOMO 2 & 6.49 & 23 & 1 & 5 & 6 & 17 & 2 & 4 \\
\hline & Hомо 3 & 6.51 & 62 & 4 & 0 & 0 & 0 & 0 & 0 \\
\hline & номо 4 & 6.54 & 12 & 0 & 0 & 0 & 21 & 0 & 0 \\
\hline & HOMO 5 & 6.56 & 0 & 0 & 0 & 0 & 61 & 4 & 0 \\
\hline \multirow[t]{8}{*}{$\mathrm{Ru}-\mathrm{Z2}^{\mathrm{Me}}$} & LUMO+2 & 1.29 & 0 & 0 & 0 & 0 & 62 & 11 & 1 \\
\hline & LUMO+1 & 1.42 & 2 & 8 & 27 & 25 & 2 & 7 & 26 \\
\hline & LUMO & 1.43 & 62 & 12 & 1 & 0 & 0 & 0 & 0 \\
\hline & номо & 5.14 & 8 & 13 & 18 & 12 & 10 & 15 & 20 \\
\hline & НОМо 1 & 5.59 & 16 & 19 & 13 & 3 & 16 & 17 & 11 \\
\hline & HOMO 2 & 6.43 & 0 & 0 & 0 & 0 & 62 & 4 & 0 \\
\hline & номо 3 & 6.48 & 17 & 2 & 4 & 6 & 24 & 1 & 5 \\
\hline & Hомо 4 & 6.50 & 56 & 4 & 1 & 1 & 3 & 0 & 1 \\
\hline \multirow[t]{9}{*}{ Ru-Z2fix ${ }^{\mathrm{Me}}$} & LUMO+2 & 0.93 & 2 & 10 & 28 & 19 & 2 & 10 & 27 \\
\hline & LUMO+1 & 1.42 & 63 & 12 & 1 & 0 & 0 & 0 & 0 \\
\hline & LUMO & 1.46 & 0 & 0 & 0 & 0 & 64 & 12 & 1 \\
\hline & номо & 5.18 & 9 & 14 & 19 & 12 & 9 & 14 & 19 \\
\hline & Номо 1 & 5.52 & 15 & 18 & 13 & 2 & 15 & 18 & 14 \\
\hline & НОмо 2 & 6.42 & 15 & 4 & 8 & 38 & 14 & 4 & 7 \\
\hline & номо 3 & 6.51 & 62 & 4 & 0 & 0 & 0 & 0 & 0 \\
\hline & номо 4 & 6.55 & 12 & 0 & 0 & 0 & 22 & 0 & 0 \\
\hline & номо 5 & 6.55 & 1 & 0 & 0 & 0 & 60 & 4 & 0 \\
\hline
\end{tabular}

${ }^{a}$ Vil, Vi2 $=-\mathrm{CH}=\mathrm{CH}-$ entities attached to the Ru1 or Ru2 site. ${ }^{b} \mathrm{Ph} 1$ and $\mathrm{Ph} 2=$ phenyl rings close to Ru1 or Ru2. ${ }^{c}$ Total contribution from ethylenic groups linking the phenyl rings.

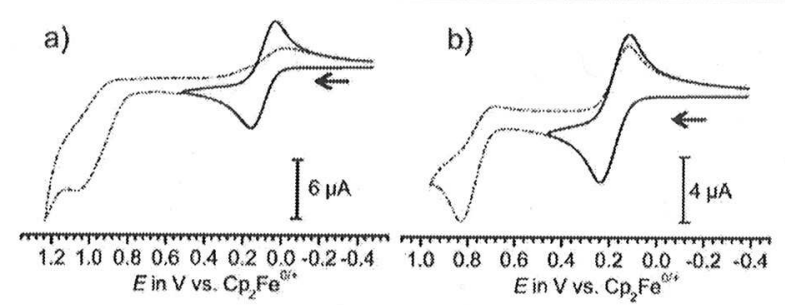

c)

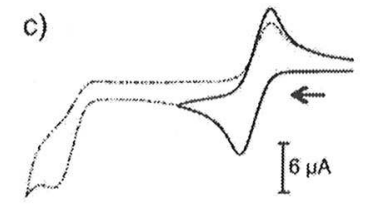

d)

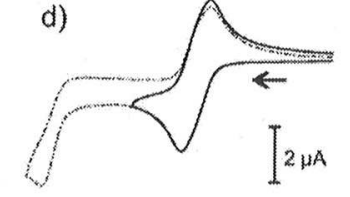

$1.21 .0 \quad 0.8 \quad 0.6 \quad 0.4 \quad 0.2 \quad 0.0-0.2-0.4 \quad 1.00 .80 .60 .40 .20 .0+0.2-0.4-0.6$ Ein V vs. $\mathrm{Cp}_{2} \mathrm{Fe}_{\mathrm{e}}$

Ein V V C C . Fé

Figure 11. Voltammograms of (a) Ru E2, (b) Ru E1, (c) Ru Z2 and (d) $\mathrm{Ru} \mathrm{Z2fix}$ in $\mathrm{CH}_{2} \mathrm{Cl}_{2} / \mathrm{NBu}_{4} \mathrm{PF}_{6}(0.1 \mathrm{M}, \mathrm{rt}, v=0.1 \mathrm{~V} / \mathrm{s})$.

and may be either smaller $\left(\Delta E_{1 / 2} \leq 36 \mathrm{mV}\right)$ or larger $\left(\Delta E_{1 / 2} \geq\right.$ $36 \mathrm{mV}$ ) than those for a Nernstian one electron process. ${ }^{36}$ As will be discussed in a later section, stepwise oxidation by slowly scanning through the first oxidation waves of diruthenium complexes Ru E2 and Ru Z2fix clearly established their two electron nature and the presence of two successive one electron events. Similar observations have already been reported for other polyenes, e.g., carotenoid derivatives. ${ }^{37}$ Individual half wave potentials of the two underlying one electron couples were determined by digital simulation of the voltammograms (DigiSim, see the SI for details), and the results are illustrated in Figure 12 and summarized in Table 5. Their splitting amounts to just 49 (Ru E2) or $74 \mathrm{mV}$ (Ru Z2fix). While being too small to allow for a resolution of the composite wave into two individual ones, they are still larger than the $36 \mathrm{mV}$ limit

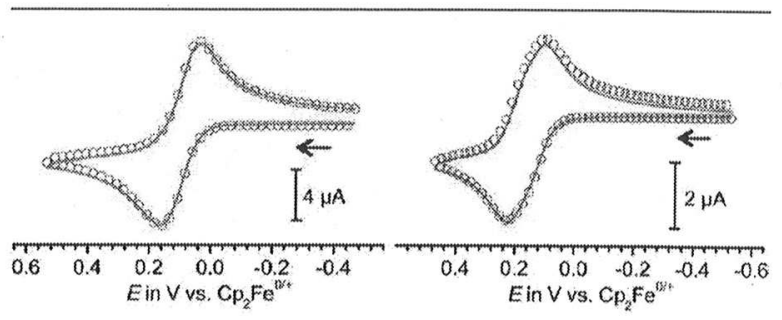

Figure 12. Experimental (red lines) and simulated (DigiSim, circles) voltammograms of $\mathbf{R u} \mathbf{E 2}$ (left) and $\mathbf{R u} \mathbf{Z 2 f i x}$ (right) in $\mathrm{CH}_{2} \mathrm{Cl}_{2} /$ $\mathrm{NBu}_{4} \mathrm{PF}_{6}$. 
Table 5. Electrochemical Parameters of the Stilbenyl Ruthenium Complexes As Determined from Digital Simulation of Their Voltammograms

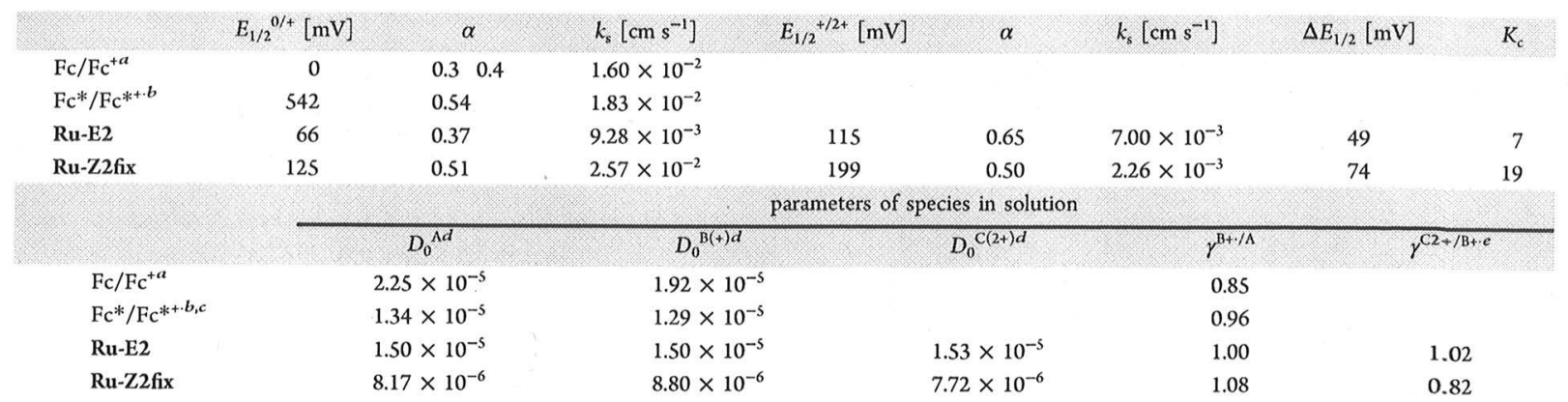

${ }^{a} \mathrm{In} \mathrm{CH}_{2} \mathrm{Cl}_{2} / \mathrm{NBu}_{4} \mathrm{ClO}_{4}$; from ref 40. ${ }^{b}$ From ref $41 .{ }^{c} \mathrm{D}_{0}{ }^{\mathrm{A}}$ value from ref $42 .{ }^{d}$ Diffusion coefficient in $\mathrm{cm}^{2} \mathrm{~s}^{-1}$. ${ }^{e} \mathrm{Ratio}$ of diffusion coefficients in adjacent oxidation states.

expected in the case of two interconnected, but mutually insulated redox centers. ${ }^{35,38}$ These redox centers are readily identified as the two styryl ruthenium subunits which are interconnected via the central ethylenic bond. On the basis of the observation of two consecutive one electron steps, the radical cations resulting from one electron oxidation are to be considered as being mixed valent. While there is no direct relation between the half wave potential splitting and the strength of the electronic interaction between coupled redox sites, ${ }^{2 i, 15 a, 39}$ the rather small values of $\Delta E_{1 / 2}$ and of the comproportionation constant $K_{c}$ (Table 5) suggest that they belong to Class II according to the Robin and Day classification scheme ${ }^{14}$ with only a weak or modest coupling between them. We will describe in a later section how we can directly probe for these interactions and quantitatively measure their magnitude by IR spectroelectrochemistry in making use of the $\mathrm{Ru}-\mathrm{CO}$ "markers". Before turning to that issue we address the odd electrochemical behavior of $\mathbf{R u ~ Z 2}$, which could finally be traced to an electrocatalytic isomerization.

Electrocatalytic Isomerization of Ru-Z2 to Ru-E2. Despite the rather substantial differences in peak potentials observed for other $E / Z$ isomeric pairs of organic stilbenes, ${ }^{6 \mathrm{~b}}$ the CVs of Ru E2 and Ru Z2 appeared to be basically identical. This prompted us to study the electrochemical behavior of $\mathbf{R u}$ Z2 in greater detail. A close inspection of voltammograms recorded during the first scans in freshly prepared electrolyte solutions revealed a small inflection on the cathodic realm of the forward peak (see Figure S12 of the SI) which disappeared after a few scans. This inflection is highly reminiscent of a catalytic prewave as it is sometimes seen in electrotriggered isomerization or substitution reactions. ${ }^{43}$ This overall behavior roused our suspicion that electrocatalyzed $Z \rightarrow E$ isomerization may operate for oxidized $\mathbf{R u ~ Z 2}$, noting that such processes are well precedented for the oxidized or reduced forms of $Z$ stilbenes. ${ }^{6,44}$ In order to directly probe for such isomerization, we devised an experiment that builds on the distinct UV/vis spectra of complexes $\mathbf{R u} \mathbf{E} 2$ and $\mathbf{R u} \mathbf{Z} 2$. To a freshly prepared solution of $\mathbf{R u ~ Z 2}$ we added substoichiometric amounts of ferrocenium hexafluorophosphate, $\mathrm{Fc}^{+} \mathrm{PF}_{6}^{-}$. As it is evident from Table S, electron transfer from $\mathbf{R u} \mathbf{Z 2}$ to the ferrocenium ion is an endergonic process. It is already endergonic by $66 \mathrm{mV}$, i.e. $\sim 6.5 \mathrm{~kJ} / \mathrm{mol}$, for Ru E2. Given the fact that oxidation potentials of $Z$ stilbenes are usually $110-150 \mathrm{mV}$ higher than those of their $E$ isomers and given the higher oxidation potential of Ru Z2fix when compared to Ru E2, this should be even more so for Ru Z2. The chemical equilibria in eqs 1 and 2 should therefore be displaced far to the left with only little Ru $\mathbf{Z 2}^{n+}$ formed. Given the small separation of half wave potentials between the first and the second oxidation processes of the stilbenyl complexes, the disproportionation equilibrium in eq 3 must also be taken into account. Following the principle of Le Châtelier, an irreversible isomerization of $\mathbf{R u} \mathbf{Z 2}^{\mathbf{n +}}$ to its thermodynamically more stable $E$ isomer, $\mathbf{R u} E 2^{n+}$ (eq 4), will siphon any $\mathbf{R u ~} \mathbf{Z 2}^{n+}$ out of the former, reversible redox equilibria and drag the chemical reaction, despite the unfavorable equilibrium constant of the initial step(s). The final step of the reaction is exergonic back electron transfer from ferrocene or from $\mathbf{R u ~ Z 2}$ to $\mathbf{R u} \mathbf{E 2}^{n+}$ (eqs 5, 6) and ultimately yields neutral Ru E2. Please note here that, because of the coupled irreversible oxidation, the peak position of the catalytic prewave does not correspond to the thermodynamic half wave potential of the $\mathbf{R u ~ Z 2}^{0 /+}$ couple, ${ }^{43 a, 45}$ which is expected to be positive of the $\mathrm{Ru} E 2^{0 /+}$ one. ${ }^{6 \mathrm{~b}} \mathrm{~A}$ cross reaction between $\mathbf{R u} \mathbf{Z 2}$ and $\mathbf{R u ~ E 2} 2^{n+}$ would then trigger another reaction cycle and render the overall process electrocatalytic. This is exactly what we observed in this experiment. In the presence of substoichiometric amounts of $\mathrm{Fc}^{+} \mathrm{PF}_{6}^{-}, \mathbf{R u ~ Z 2}$ is partially converted to neutral Ru E2 within $\sim 5-10 \mathrm{~min}$. Figure 13 depicts two representative sets of spectra accumulated

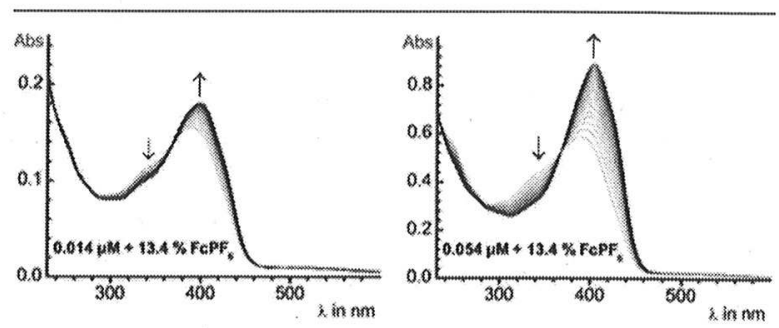

Figure 13. Electrocatalytic isomerization of $\mathbf{R u} \mathbf{Z 2}$ to $\mathbf{R u} \mathbf{E 2}$ in the presence of substoichiometric amounts of the ferrocenium ion at two different initial concentrations. See Figure 10 for the UV/vis spectrum of genuine Ru E2.

during the isomerization process and demonstrate that the isomerization occurs with clean isosbestic points. We should point out here that none of the intense Vis/NIR absorptions of $\mathbf{R u} \mathrm{E2}^{n+}$ or $\mathbf{R u} \mathbf{Z 2}^{n+}$ (vide infra) are observed at any stage of the reaction and that, in the absence of $\mathrm{Fc}^{+} \mathrm{PF}_{6}^{-}, \mathbf{R u ~ Z 2}$ is stable under these conditions.

$$
\mathbf{R u}-\mathbf{Z} 2+\mathrm{Fc}^{+} \rightleftarrows \mathbf{R u}-\mathbf{Z 2}^{\bullet+}+\mathrm{Fc}
$$




$$
\begin{aligned}
& \mathbf{R u}-\mathbf{Z 2}^{\circ+}+\mathrm{Fc}^{+} \rightleftarrows \mathbf{R u}-\mathbf{Z 2}^{2+}+\mathrm{Fc} \\
& 2 \mathbf{R u}-\mathbf{Z 2}^{\circ+} \rightleftarrows \mathbf{R u}-\mathbf{Z} 2+\mathbf{R} \mathbf{u}-\mathbf{Z 2}^{2+} \\
& \mathbf{R u}-\mathbf{Z 2}^{n+} \rightarrow \mathbf{R u}-\mathbf{E} 2^{n+} \\
& \mathbf{R u}-\mathbf{E} 2^{n+}+n \mathrm{Fc} \rightleftarrows \mathbf{R u}-\mathbf{E} 2+n \mathrm{Fc}^{+} \\
& \mathbf{R u}-\mathbf{E} 2^{n+}+n \mathbf{R u}-\mathbf{Z} 2 \rightleftarrows \mathbf{R u}-\mathbf{E} 2+n \mathbf{R u}-\mathbf{Z 2}^{(3-n)+}
\end{aligned}
$$

Under the conditions of high dilution and in the presence of substoichiometric amounts of the weak oxidant $\mathrm{Fc}^{+} \mathrm{PF}_{6}^{-}$the isomerization reaction can, however, not proceed to completion. This is clearly seen from the ratio of the absorbances at the peak wavelengths of Ru E2 after the reaction has come to an end and of original $\mathbf{R u} \mathbf{Z 2}$ and its comparison with those observed for pristine samples of these compounds (Figure 10). Even with the same percentage amount of the oxidant, conversion decreases at lower initial concentration of $\mathbf{R u ~ Z 2}$ (compare the two data sets in Figure 13). This restriction, however, vanishes during potential sweeps when the electrode provides an electron sink of infinite capacity. Complete isomerization is thus readily accomplished under the conditions of cyclic voltammetry and spectroelec trochemistry (vide infra).

As for the $Z \rightarrow E$ isomerization itself, there are various mechanistic alternatives that differ with respect to whether this process occurs at the radical cation or at the dication level and whether it follows a monomolecular or a bimolecular process. Investigations of electrotriggered isomerizations of stilbenes have provided precedence for several different mechanistic alternatives. ${ }^{6,44,46} \mathrm{~A}$ more detailed discussion of that issue is, however, beyond the scope of the present paper and will be reported separately. Suffice to say that the main impact of redox processes is to depopulate the HOMO (oxidation) or to populate the LUMO (reduction). Both frontier orbitals receive strong contributions from the central ethylenic bond with a bonding interaction for the HOMO, but an antibonding one for the LUMO. Oxidation or reduction thus have both the effect of weakening the central $\mathrm{C}=\mathrm{C}$ bond, thereby decreasing the energy barrier for $Z \rightarrow E$ isomerization.

Spectroscopic Investigations on the Oxidized Forms. The chemical reversibility of the first or first two oxidation waves of the stilbenyl ruthenium complexes allowed us to generate and investigate their various oxidized forms inside an optically/NIR/IR transparent thin layer electrolysis cell (see the Experimental Section in the SI for details). Upon oxidation, vinyl ruthenium complexes $\mathrm{RCH}=\mathrm{CH}-\mathrm{RuCl}(\mathrm{CO})\left(\mathrm{PR}_{3}\right)_{2} \mathrm{~L}$ usually show a blue shift of $\nu(\mathrm{CO})$ for the ruthenium bonded carbonyl ligand as well as more irregular shifts of the $\mathrm{Ru}-$ $\mathrm{CH}=\mathrm{CH}$ and the $\mathrm{HC}=\mathrm{CH}$ and ring vibrations of the attached aryl substituent. The former results from a decrease of $\mathrm{Ru}(\mathrm{d} \pi)$ to $\mathrm{CO}\left(\pi^{*}\right)$ back donation. Rather small $\mathrm{CO}$ band shifts provide one piece of evidence for the only moderate ruthenium contribution to the HOMO, which is the relevant redox orbital in such systems. In fact, our calculations indicate that the metal contribution to the HOMO amounts to $16-19 \%$ (see Table 4). A steady decrease of the oxidation induced blue shift of the $\mathrm{CO}$ stretch with respect to the neutral, $\Delta \tilde{\nu}(\mathrm{Ru}-\mathrm{CO})$, with increasing conjugation length has been documented for a series of complexes with hexenyl, styryl, and vinylpyrenyl ligands. ${ }^{12 \mathrm{~h}}$ Even for the simple hexenyl complex, the CO band shift is just about half of that of $130 \mathrm{~cm}^{-1}$ observed for the $\mathrm{Ru}-$
$\mathrm{CO}_{3}\left(\mathrm{PR}_{3}\right)_{2}$ benchmark systems of Gladfelter et al. ${ }^{47}$ Most relevant for the present study is the styryl complex $\mathrm{PhCH}=$ $\mathrm{CH}-\mathrm{RuCl}(\mathrm{CO})\left(\mathrm{P}^{\mathrm{i}} \mathrm{Pr}_{3}\right)_{2}$, where $\Delta \tilde{\nu}(\mathrm{Ru}-\mathrm{CO})$ amounts to 65 $\mathrm{cm}^{-1}$. The smaller $\Delta \tilde{\nu}(\mathrm{Ru}-\mathrm{CO})$ value of $56 \mathrm{~cm}^{-1}$ observed for complex Ru E1 is therefore a token of an even smaller metal contribution to the HOMO on further extension of the unsaturated organic ligand (Figure 14 and Table 3). Further

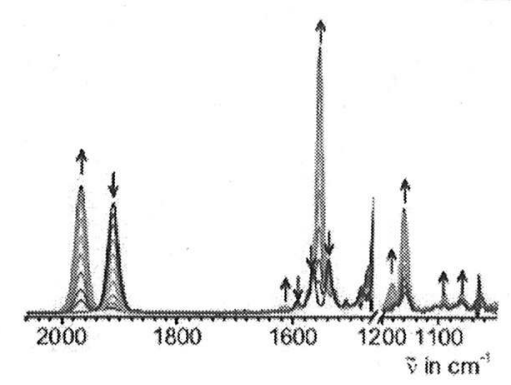

Figure 14. Spectroscopic changes on oxidation of Ru E1 inside a thin layer electrolysis cell (DCE, $0.2 \mathrm{M} \mathrm{NBu}_{4} \mathrm{PF}_{6}$ ).

changes occur in the spectral region of the $\nu(\mathrm{C}=\mathrm{C})$ and aryl ring vibrations. These include the appearance of a new weak band at $1612 \mathrm{~cm}^{-1}$, a red shift of other $\nu(\mathrm{C}=\mathrm{C})$ vibrations. and the growth of a highly intense band at $1555 \mathrm{~cm}^{-1}$. Another spectroscopic window with little obstruction by IR absorptions of the DCE/ $\mathrm{NBu}_{4}{ }^{+} \mathrm{PF}_{6}{ }^{-}$supporting electrolyte (DCE $=1,2$ $\left.\mathrm{C}_{2} \mathrm{H}_{4} \mathrm{Cl}_{2}\right)$ opens in the $1200-1000 \mathrm{~cm}^{-1}$ range, where $\nu(\mathrm{C}-$ $\mathrm{C}), \quad \delta(\mathrm{C}-\mathrm{H})$, and in plane ring deformation modes ap pear. ${ }^{5 b, 28,29,30 c}$ A set of bands at 1090 and $1061 \mathrm{~cm}^{-1}$ are basically unaffected by oxidation and are thus assigned as $\nu(\mathrm{C}-$ C) of the $P^{i} \operatorname{Pr}_{3}$ ligands. Other bands at 1175 and $1159 \mathrm{~cm}^{-1}$, while experiencing only slight shifts, gain significant intensity when compared to their neutrals. On the basis of their close resemblance to IR and Raman active $\mathrm{C}_{\mathrm{ph}}-\mathrm{C}_{\mathrm{ph}}, \mathrm{C}_{\mathrm{e}}-\mathrm{C}_{\mathrm{ph}}$, and $\mathrm{CH}$ deformation modes of stilbenes we propose a similar assignment here. The observation of a weak band for that mode in the neutral and the intensity gain for all these vibrations upon oxidation are likely a consequence of the lower symmetry of the unsymmetrically substituted stilbenyl core of Ru El and an increased dipole moment change for these vibrations at the radical cation level, where the hole largely localizes on the electron rich styryl ruthenium subunit.

The first composite voltammetric wave of the dinuclear complexes Ru E2 and Ru Z2fix comprises the consecutive 0/+ and $+/ 2+$ steps. As a consequence, IR spectroscopic changes follow a more complicated pattern. When slowly scanning through this wave one first observes an intermediate pattern of two $\mathrm{Ru}-\mathrm{CO}$ bands where the one at lower energy is slightly blue of the $\mathrm{CO}$ band position in the neutral (Figure 15, Table 3 ). Concomitant spectroscopic changes in the 1650-1480 $\mathrm{cm}^{-1}$ and the $1200-1000 \mathrm{~cm}^{-1}$ regions resemble those observed for Ru E1 with a decrease of the initial bands for the $\mathrm{C}=\mathrm{C}, \mathrm{C}-\mathrm{H}$, and ring modes and the growth of new, more intense ones at lower energies. The higher intensities of the shifted $\nu(\mathrm{C}=\mathrm{C})$ bands for the radical cations imply again an increasing dipole moment change during the respective vibration and, probably, also a higher dipole moment in the ground state. Of particular note is the high intensity of the 1150 $\mathrm{cm}^{-1}$ vibration in the case of $\mathbf{R u ~ E 2}{ }^{\circ+}$ and the splitting of this band into two different absorptions, each of medium intensity, for $\mathbf{R u ~ Z 2 f i x}{ }^{\circ+}$. At later stages of the electrolysis and after 

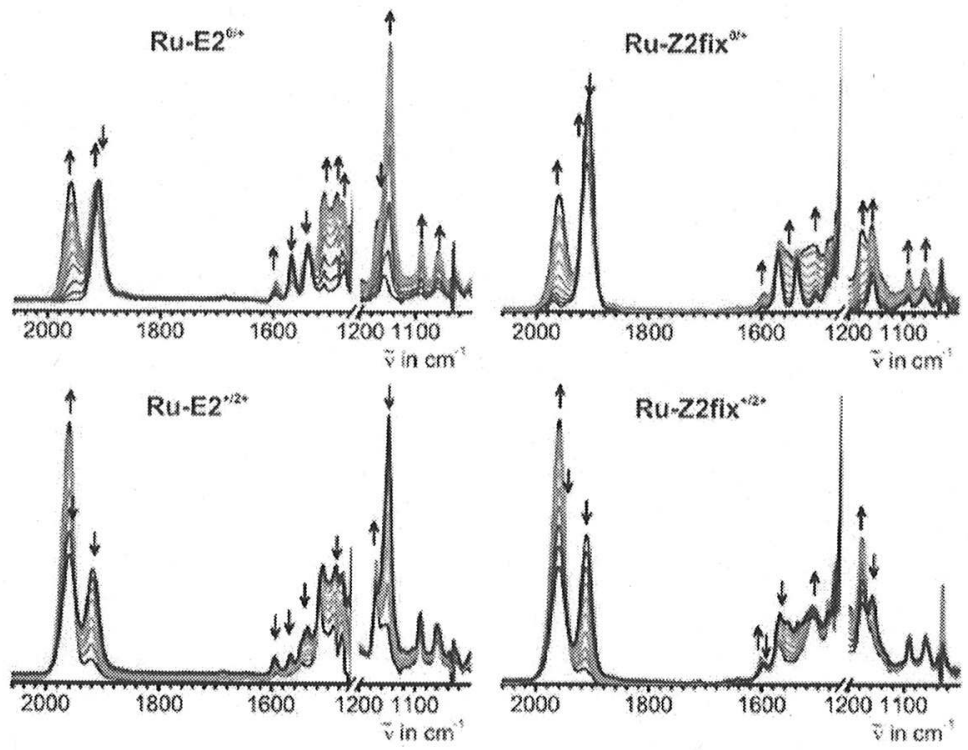

Figure 15. Spectroscopic changes on the first (top) and second (bottom) oxidation of Ru E2 (left) and Ru Z2fix (right) inside a thin layer electrolysis cell (DCE, $0.2 \mathrm{M} \mathrm{NBu}_{4} \mathrm{PF}_{6}$ ).

reaching higher potentials, the intensities of these bands pass through a maximum and then decrease along with some additional band shifts. Such behavior is most obvious for the highly intense $1150 \mathrm{~cm}^{-1}$ band of $\mathrm{Ru} \mathrm{E2}^{\circ+}$ and the multiple $\mathrm{C}=\mathrm{C}$ modes of $\mathbf{R u} \mathbf{Z 2 f i x}^{\circ+}$. At the same time, the lower energy $\mathrm{Ru}-\mathrm{CO}$ band disappears while the one at the higher energy intensifies and experiences a further, incremental blue shift. All these observations are well accommodated by a stepwise oxidation of the neutral complexes by two electrons with distinct spectroscopic signatures of the intermediate radical cations. In spite of the rather small comproportionation constants, the latter are therefore clearly observable as separate species. This statement finds further support from our observation of extremely broad and intense features in the $4500-6000 \mathrm{~cm}^{-1}$ region, whose growth and disappearance parallels that of other radical cation bands in the mid IR. As will be discussed in the following section, these bands are due to low energy electronic transitions.

Quantum chemistry provides a qualitatively satisfactory fit with our experimental data. In the course of oxidation an electron is withdrawn from the bridge dominated $\pi$ HOMO (Ru4d contribution 16-19\%). It was shown that larger admixture of HF exchange and/or the inclusion of solvation effects is necessary for qualitatively correct descriptions of electron delocalization in mixed valent systems of that type $\mathrm{pd}, 9 \mathrm{c}, 10 \mathrm{f}, 48^{2}$ and hence the interpretation of oxidation induced CO band shifts in the IR. After inclusion of PCM solvent correction and the use of the hybrid M05 functional the calculated sequence of $\mathrm{CO}$ frequencies listed in Table 6 reproduces the experimental data reasonably well. Geometry optimization of the radical cations leads to a broken symmetry solution and to a split of the originally degenerate CO stretching frequencies for the radical cations.

Electronic spectra of stilbenyl radical cations are charac terized by intense low energy absorptions at $\sim 13250$ and 20000 $\mathrm{cm}^{-1}(750$ and $500 \mathrm{~nm}){ }^{5 \mathrm{a}, 49}$ These so called A and B bands emanate from the HOMO $-3 \rightarrow$ HOMO and the HOMO $\rightarrow$ LUMO excitations (using the orbital denominations of the
Table 6. Comparison of G09/M05/PCM $\left(\mathrm{CH}_{2} \mathrm{Cl}_{2}\right)$ Calculated CO Stretching Frequencies for $\mathrm{Ru} \mathrm{E1}^{\mathrm{Me} n+}, \mathrm{Ru}$ $\mathrm{E}^{\mathrm{Me}{ }^{n+}}, \mathrm{Ru} \mathrm{Z} 2$ and Ru Z2fix ${ }^{\mathrm{Me} n+}$ with Experimental Ones

\begin{tabular}{|c|c|c|}
\hline & calculated $^{a}$ & experimental \\
\hline & $\nu_{1}(\mathrm{CO}), \nu_{2}(\mathrm{CO})^{b}$ & $\nu_{1}(\mathrm{CO}), \nu_{2}(\mathrm{CO})^{b}$ \\
\hline Ru-E1 & 1908 & 1911 \\
\hline $\mathrm{Ru}-\mathrm{E} 1^{\circ+}$ & 1935, & 1967, \\
\hline Ru-E2 & 1911, 1913 & 1911 \\
\hline $\mathrm{Ru}-\mathrm{E} 2^{\circ+}$ & 1918,1950 & 1921, 1954 \\
\hline \multirow[t]{2}{*}{$\mathrm{Ru}-\mathrm{E}^{2+}$} & $1968,1972^{c}$ & \\
\hline & $1976,1977^{d}$ & 1964 \\
\hline Ru-Z2 & 1908,1909 & 1911 \\
\hline Ru-Z2fix & 1908,1909 & 1910 \\
\hline Ru-Z2fix ${ }^{\circ+}$ & 1910, 1969 & 1913,1956 \\
\hline \multirow[t]{2}{*}{ Ru-Z2fix ${ }^{2+}$} & $1977,1979^{c}$ & \\
\hline & $1974,1978^{d}$ & 1963 \\
\hline
\end{tabular}

${ }^{a}$ Calculated frequencies are scaled by a factor of $0.932 .{ }^{b} \nu_{1}$ and $\nu_{2}$ denote the $\mathrm{Ru}-\mathrm{CO}$ stretches of the $\mathrm{CO}$ ligands bonded to atoms Rul and Ru2, respectively. ${ }^{\circ}$ Calculated for UKS singlet diradical state. ${ }^{d}$ Calculated for UKS triplet state.

corresponding neutral). The radical cations of $Z$ diphenyle thene $\left(\tilde{v}=13300 \mathrm{~cm}^{-1}\right)$ and of the more distorted $Z 1,2$ diethyl 1,2 diphenylethene $\left(\tilde{\nu}=14800 \mathrm{~cm}^{-1}\right)$ provide in structive examples of how the energy of the A band increases with increasing torsion at the central ethylene bond. As for the neutrals, deviations from coplanarity are accompanied by a loss of vibrational fine structure. ${ }^{49}$

The spectrum of electrogenerated Ru E1 ${ }^{\circ+}$ (Figure 16) shows all the features of organic $E$ stilbenyl radical cations. As for the neutral, the A band is notably red shifted from that of oxidized 1,2 diphenylethene (Table 7) and closer to that of the $E, E$ distyrylbenzene $\left(\tilde{\nu}=8850 \mathrm{~cm}^{-1}\right)^{50}$ or the E,E 1,4 bis(4 methylstyryl)benzene radical cations $\left(\tilde{\nu}=8330 \mathrm{~cm}^{-1}\right)$. ${ }^{51}$ The substantial absorptivity and the vibrational fine structure of the A band clearly indicate its $\pi \rightarrow \pi^{*}$ parentage and that the planarity of the neutral form is retained or even increased. 


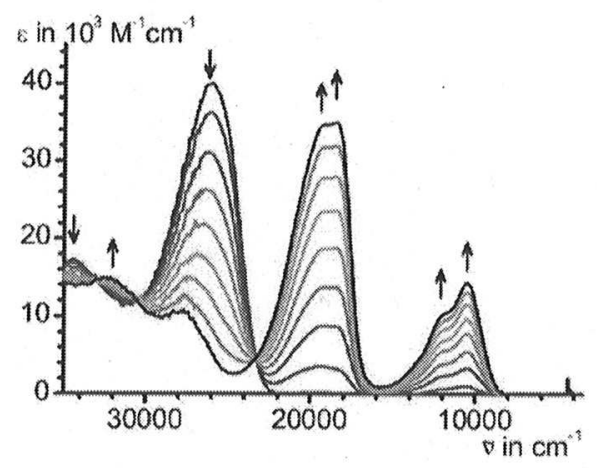

Figure 16. Spectroscopic changes during the oxidation of Ru E1 inside a thin layer electrolysis cell (rt, DCE/0.2 $\mathrm{M} \mathrm{NBu}_{4} \mathrm{PF}_{6}$ ).

Radical cations of the dinuclear complexes $\mathbf{R u} \mathbf{E} 2$ and $\mathbf{R u}$ Z2fix are observed as intermediates in the oxidation process. They are readily identified by their distinct low energy absorptions that extend from the NIR into the mid IR and peak at $\sim 4900-5000 \mathrm{~cm}^{-1}$ (Figure 17, Table 7). In passing, we note that their energies are much smaller than those observed for oxidized 4,4' (bisdiphenylamino) $E$ stilbene $\left.\left(6760 \mathrm{~cm}^{-1}\right)\right)^{52}$ $E, E$ distyryl $4,4^{\prime} E$ stilbene $\left(6944 \mathrm{~cm}^{-1}\right)^{53}$ and come close to those observed for the polarons (solitons) of fully conjugated, unsubstituted PPVs, where a limiting value of $5650 \mathrm{~cm}^{-1}(1770$ $\mathrm{nm}, 0.7 \mathrm{eV}$ ) is reached. ${ }^{54}$ They also resemble the radical cations of donor substituted, longer chain OPVs like an $E, E$ distyryl $E$ stilbene built exclusively from 2,5 dialkoxysubstituted benzenes $\left(5300 \mathrm{~cm}^{-1}\right){ }^{55}$ The position of this low energy NIR band is virtually identical for $\mathbf{R u ~ E 2}^{\circ+}$ and $\mathbf{R u ~ Z 2 f i x}{ }^{\circ+}$. We note,
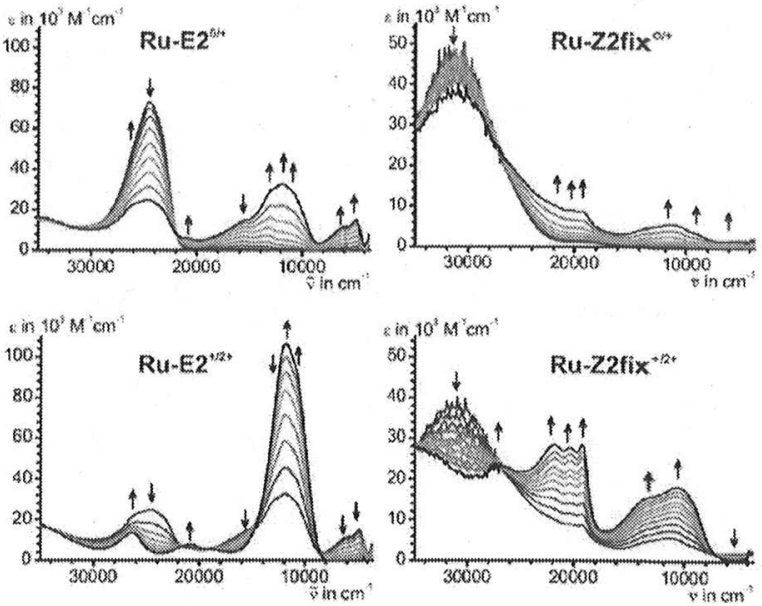

Figure 17. Spectroscopic changes during the first (top) and second (bottom) oxidation of Ru E2 (left) and Ru Z2fix (right) inside a thin layer electrolysis cell (rt, DCE/0.2 $\mathrm{M} \mathrm{NBu}_{4} \mathrm{PF}_{6}$ ).

however, that this band is less broad and considerably more intense for $\mathbf{R u} \mathbf{E} 2^{\mathbf{}}{ }^{++}$than for $\mathbf{R u} \mathbf{Z 2 f i x}^{\mathbf{}}{ }^{\mathbf{}}$. The latter is a likely consequence of the higher torsion at the central ethylenic double bond. ${ }^{\mathrm{Sa}, 49}$ Other absorptions at higher energies also vary little with double bond configuration.

Further oxidation results in the disappearance of the band at the lowest energy, the increase of the other one near 11000$12000 \mathrm{~cm}^{-1}$ and the growth of new bands at even higher energies. The prominent feature in the electronic spectrum of $\mathrm{Ru} \mathrm{E2}{ }^{2+}$ is the new $\mathrm{A}$ band at $11800 \mathrm{~cm}^{-1}$. The equivalent band

Table 7. Vis/NIR Band Maxima and Extinction Coefficients of the Stilbenyl Ruthenium Complexes in Their Various Oxidation States

\begin{tabular}{|c|c|c|c|c|}
\hline & \multicolumn{4}{|c|}{ neutrals } \\
\hline & \multicolumn{2}{|c|}{$\begin{array}{c}\text { B-band } \\
\tilde{\nu}_{\max }^{a}(\varepsilon)^{b}\end{array}$} & $\begin{array}{c}\text { A-band } \\
\hat{\nu}_{\max }^{a}(\varepsilon)^{b}\end{array}$ & $\begin{array}{c}\mathrm{LMCT} \\
\tilde{\nu}_{\max }^{a}(\varepsilon)^{b}\end{array}$ \\
\hline Ru-E1 & \multicolumn{2}{|c|}{$35100(17100)$} & $26600(40100)$ & $19400(500)$ \\
\hline Ru-E2 & & $24600(73000)$ & $19600(1300)$ \\
\hline $\mathrm{Ru}-\mathrm{Z2}$ & \multirow{2}{*}{\multicolumn{2}{|c|}{$29600(22900)$}} & $25300(40600)$ & $19600(1200)$ \\
\hline \multirow{3}{*}{ Ru-Z2fix } & & & $31100(46100)$ & $19400(800)$ \\
\hline & \multicolumn{4}{|c|}{ radical cations } \\
\hline & $\begin{array}{c}\text { D-band } \\
\tilde{\nu}_{\max }^{a}(\varepsilon)^{b}\end{array}$ & $\begin{array}{c}\text { C.band } \\
\tilde{\nu}_{\max }^{a}(\varepsilon)^{b}\end{array}$ & $\begin{array}{c}\text { B-band } \\
\tilde{\nu}_{\max }^{a}(\varepsilon)^{b}\end{array}$ & $\begin{array}{c}\text { A-band } \\
\tilde{\nu}_{\max }^{a}(\varepsilon)^{b}\end{array}$ \\
\hline \multirow[t]{2}{*}{ Ru-E1 ${ }^{\circ+}$} & $32200(15000)$ & $27700(10800)$ & $18500(34900)$ & $10500(14300)$ \\
\hline & $35300(14500)$ & & $19200(34700)$ & $12000(\mathrm{sh})$ \\
\hline \multirow[t]{3}{*}{ Ru-E2 ${ }^{\circ+}$} & $36400(17800)$ & $24600(31300)$ & $12000(22000)$ & $4900(14400)$ \\
\hline & & & $13000(21900)$ & $5900(11200)$ \\
\hline & & & $15300(13500)$ & \\
\hline \multirow[t]{3}{*}{ Ru-Z2fix ${ }^{0+}$} & $31000(40300)$ & $19300(8700)$ & $11600(5800)$ & $5000(1900)$ \\
\hline & \multicolumn{4}{|c|}{ dications } \\
\hline & $\begin{array}{c}\text { D-band } \\
\tilde{\nu}_{\max }^{a}(\varepsilon)^{b}\end{array}$ & $\begin{array}{c}\text { C-band } \\
\tilde{\nu}_{\max }^{a}(\varepsilon)^{b}\end{array}$ & $\begin{array}{c}\text { B-band } \\
\tilde{\nu}_{\max }^{a}(\varepsilon)^{b}\end{array}$ & $\begin{array}{c}\text { A-band } \\
\tilde{\nu}_{\max }^{a}(\varepsilon)^{b}\end{array}$ \\
\hline $\mathrm{Ru}-\mathrm{E} 2^{2+}$ & $36400(19700)$ & $26400(13500)$ & $\begin{array}{l}20800(7800) \\
18900(\mathrm{sh})\end{array}$ & $11800(106500)$ \\
\hline \multirow[t]{2}{*}{ Ru-Z2fix ${ }^{2+}$} & $36400(29200)$ & $27200(23900)$ & $19200(28400)$ & $10700(18300)$ \\
\hline & & & $20300(27800)$ & $12800(\mathrm{sh})$ \\
\hline
\end{tabular}

${ }^{a}$ In $\mathrm{cm}^{-1} \cdot{ }^{b}$ In L $\cdot \mathrm{mol}^{-1} \cdot \mathrm{cm}^{-1}$. 
of $\mathbf{R u ~} \mathbf{Z 2 f i x}^{2+}$ is similar in position but again much broader and weaker (Table 7). The B bands follow just the opposite order of intensities: While it is just a relatively weak unstructured feature in $\mathrm{Ru} \mathrm{E}^{2+}$ it appears as a strong, richly structured absorption in the case of Ru Z2fix ${ }^{2+}$ (Figure 17). Only few literature data seem to be available on the electronic spectra of dioxidized phenylene vinylenes of finite chain lengths that could serve as a point of comparison with our data. A broad absorption at $10100 \mathrm{~cm}^{-1}$ was reported for the E,E bis 1,4 (4 dimethylstyryl)benzene dication, ${ }^{51}$ while exhaustively doped PPVs display a broad bipolaron band at $~ 7500-4300$ $\mathrm{cm}^{-1} \cdot 54,56$ Dioxidized 1,4 divinylphenylene and stilbenyl bridged triarylamine dications display rather sharp and intense bands at 11100 and $9300 \mathrm{~cm}^{-1}$, respectively. ${ }^{16 c}$

One should add here that the high degree of chemical reversibility observed in cyclic voltammetry also holds for the considerably longer time scale of the spectroelectrochemical experiments. Spectra of $\mathbf{R u ~ E 2 ^ { \mathbf { n } + }}, \mathbf{R u} \mathbf{Z} 2 \mathbf{f} \mathbf{x i}^{\mathbf{n +}}$ collected on the reverse sweep, i. e. on back reduction to first the radical cations and then the neutrals, mirrored those observed during the forward, anodic sweep. After completion of the full cycle, the corresponding neutrals were obtained in spectroscopic yields of $>95 \%$.

The results of spectroelectrochemical studies of $\mathbf{R u} \mathbf{Z 2}$ support our previous notion of an electrocatalyzed $Z \rightarrow E$ isomerization. Scanning the potential of the thin layer cell to the onset of the oxidation wave under IR monitoring causes a rapid shift of the characteristic $\mathrm{C}=\mathrm{C}$ bands of $\mathrm{Ru} \mathrm{Z2}$ at 1537 and $1504 \mathrm{~cm}^{-1}$ to exactly their position in the $E$ isomer $\mathbf{R u ~ E 2}$, 1539 and $1508 \mathrm{~cm}^{-1}$. Similar observations were made in the UV/vis/NIR experiment.

At the initial stages of the electrolysis and after passage of a small amount of charge, the bands of $\mathbf{R u} \mathbf{Z 2}$ give way to those of Ru E2 with little formation of $\mathbf{R u ~ E 2}{ }^{\circ+}$ (see Figure S13 of the SI). The time scale of the isomerization seems, however, to vary between these two experiments. While under UV/vis/NIR monitoring $Z \rightarrow E$ isomerization required $\sim 120 \mathrm{~s}$, the IR reaction was already complete after the first two scans ( $\sim 20 \mathrm{~s})$. The only difference between these experiments is the higher concentration of the analyte in IR spectroelectrochemistry. This points, though in a somewhat circumstantial manner, to reaction kinetics for the isomerization process that are higher order in radical cation concentration. Increasing the potential further causes the gradual conversion of $\mathbf{R u} \mathbf{E} 2$ to $\mathbf{R u} \mathbf{E} 2^{\circ+}$ and then $\mathbf{R u ~ E 2} 2^{2+}$, and final back reduction gives exclusively $\mathbf{R u} \mathbf{E} 2$.

Quantitative assessment of the spectra of the radical cations of Ru E2 and Ru Z2fix is complicated by the small comproportionation constants, the overlap of some bands with those of the dications or of the neutrals and the fact that the electrolyses could not always be pursued to full conversion to the dications because of some diffusional processes inside our OTTLE cell on the long electrolysis time scale. This imposes a particular problem for the accurate determination of the $\mathrm{Ru}-\mathrm{CO}$ band positions in IR spectroscopy, where the oxidation induced shifts are rather small. Two coupled Nernst equations are needed to describe how the respective amounts of neutral $\mathrm{A}$, radical cation $\mathrm{A}^{\circ+}$ and the dication $\mathrm{A}^{2+}$ in the spectroelectrochemical experiments depend on the applied potential. Concentration profiles were calculated from the known half wave potentials of the first and the second oxidation, $E_{1 / 2}{ }^{0 /+}$ and $E_{1 / 2}^{+/ 2+}$, and under the assumption that the total complex concentration remains constant throughout the electrolysis (see Figure S14 of the SI). The only point where the concentrations of all three species can be determined is when the concentration of the radical cation reaches its maximum. At this point the concentrations of the neutral and the dication are mutually equivalent such that eq 7 holds, where $c_{0}(\mathrm{~A})$ is the total concentration of $\mathrm{A}$ in any oxidation state and $\mathrm{A}^{n+}$ represents a complex in its respective oxidation state. Gratifyingly, that point is readily identified due to the specific low energy absorptions or the intense $C=C$ IR modes of the radical cations. Iterative nonlinear curve fitting with the known spectra of the neutrals and the relative fractions of all three redox forms at the point of maximum concentration of the radical cation allowed us to calculate the authentic spectra of all redox species involved in the electron transfer sequences. The reader may consult Figure S15 of the SI for the results of the fitting procedure for the IR spectra in the range of the $\mathrm{Ru}-\mathrm{CO}$ bands.

$$
c\left(\mathrm{~A}^{0}\right)=c\left(\mathrm{~A}^{2+}\right)=\left[c_{0}(\mathrm{~A})-c\left(\mathrm{~A}^{0+}\right)\right] / 2
$$

Solutions containing the radical cations $\mathbf{R u E} 1^{\bullet+}, \mathbf{R u ~ E 2} 2^{\bullet+}$ and $\mathrm{Ru} \mathrm{Z2fix}{ }^{\circ+}$ for EPR measurements were generated by chemical oxidation of the corresponding parent neutral with one equivalent of acetylferrocenium hexafluorophosphate. At room temperature or when frozen at $103 \mathrm{~K}$ they display intense EPR signals at $g$ values that come close to the free electron value $g_{\mathrm{e}}$ of 2.0023. Spectra in frozen solution are of the axial type but the $g$ tensor anisotropy is considerably smaller than for other paramagnetic organometallic species with a more pronounced $\mathrm{Ru}(\mathrm{III})$ character. ${ }^{57}$ Room temperature solution spectra are richly structured with hyperfine splittings arising from coupling of the unpaired spin to two ${ }^{31} \mathrm{P}$ and one ${ }^{99 / 101} \mathrm{Ru}$ $\left(\mathrm{Ru} \mathrm{E1}{ }^{\circ+}\right)$ or four identical ${ }^{3 \mathrm{l}} \mathrm{P}$ and two identical ${ }^{99 / 101} \mathrm{Ru}$ nuclei $\left(\mathbf{R u ~ E 2}{ }^{\bullet+}, \mathbf{R u ~ Z 2 f i x}{ }^{\circ+}\right)$. Experimental and simulated $\mathbf{r t}$ solution spectra are compared in Figure 18, while the experimental EPR parameters and hyperfine splitting constants are compiled in Table 8. In the case of $\mathbf{R u ~ E} 1^{\circ+}$, two additional

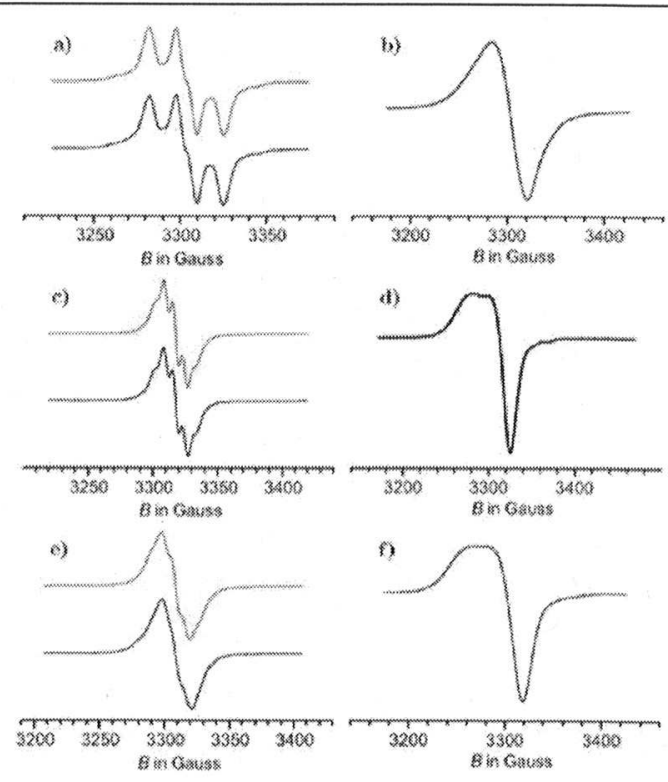

Figure 18. Experimental (black line) and simulated (red line) EPR spectra of (a) $\mathrm{Ru} \mathrm{E1}^{\circ+}$, (c) $\mathrm{Ru} \mathrm{E2}{ }^{\circ+}$, and (e) $\mathrm{Ru} \mathrm{Z2fix}{ }^{\circ+}$ in $\mathrm{CH}_{2} \mathrm{Cl}_{2}$ at rt; experimental EPR spectra at $103 \mathrm{~K}$ for (b) $\mathrm{Ru} \mathrm{E1}^{\circ+}$, (d) Ru E2 ${ }^{++}$, and (f) Ru Z2fix ${ }^{\circ+}$. 
Table 8. EPR Parameters of Radical Cations $\mathrm{Ru} \mathrm{E1}^{\circ+}, \mathrm{Ru} \mathrm{E2}^{\circ+}$, and $\mathrm{Ru} \mathrm{Z2fix}{ }^{\circ+}$ at $\mathrm{rt}$ and in Frozen Solution $(\mathrm{T}=103 \mathrm{~K})$

\begin{tabular}{|c|c|c|c|c|c|c|c|c|}
\hline & \multicolumn{4}{|c|}{$T=293 \mathrm{~K}$} & \multicolumn{4}{|c|}{$T=103 \mathrm{~K}$} \\
\hline & $g_{i s o}$ & $a\left(\left(^{9 / 101} \mathrm{Ru}\right)^{a}\right.$ & $a\left({ }^{31} \mathrm{P}\right)^{a}$ & $a\left({ }^{\prime} \mathrm{H}\right)^{a}$ & $g_{11}$ & $g_{1}$ & $\left\langle g_{\text {cale }}\right\rangle$ & $\Delta g$ \\
\hline $\mathrm{Ru}-\mathrm{E} 1^{\circ+}$ & 2.0311 & 8.17 & 15.24 & $7.15,3.12$ & 2.036 & 2.030 & 2.032 & 0.006 \\
\hline Ru-E2 ${ }^{++}$ & 2.0228 & 3.51 & 6.94 & & 2.040 & 2.031 & 2.033 & 0.009 \\
\hline Ru-Z2fix ${ }^{\circ+}$ & 2.0282 & 4.30 & 7.82 & & 2.038 & 2.025 & 2.029 & 0.013 \\
\hline${ }^{2}$ Hyperfine spli & nstants i & & & & & & & \\
\hline
\end{tabular}

Table 9. DFT Optimized (G09/M05/PCM) Selected Structural Parameters of the Stilbenyl Complexes in Different Oxidation States

\begin{tabular}{|c|c|c|c|c|c|c|c|c|c|c|}
\hline \multirow[b]{2}{*}{$n$} & \multicolumn{2}{|c|}{$\mathrm{Ru}-\mathrm{E} 1^{\mathrm{Me}}$} & \multicolumn{4}{|c|}{$\mathrm{Ru}-\mathrm{E} 2^{\mathrm{Me}}$} & \multicolumn{4}{|c|}{$\mathrm{Ru}-\mathrm{ZZZFix}^{\mathrm{Me}}$} \\
\hline & 0 & 1 & 0 & 1 & $2^{a}$ & $2^{b}$ & 0 & 1 & $2^{a}$ & $2^{b}$ \\
\hline $\mathrm{Ru} \quad \mathrm{C}_{\mathrm{v} 1}$ & 1.980 & 1.882 & 1.981 & 1.897 & 1.877 & 1.883 & 1.983 & 1.882 & 1.882 & 1.883 \\
\hline $\mathrm{Ru} \quad \mathrm{Cl}$ & 2.473 & 2.444 & 2.474 & 2.451 & 2.442 & 2.439 & 2.474 & 2.444 & 2.439 & 2.438 \\
\hline $\mathrm{Ru} \quad \mathrm{P}$ & 2.359 & 2.387 & 2.361 & 2.378 & 2.388 & 2.390 & 2.360 & 2.387 & 2.391 & 2.391 \\
\hline $\mathrm{Ru} \quad \mathrm{C}(\mathrm{CO})$ & 1.813 & 1.846 & 1.813 & 1.838 & 1.851 & 1.854 & 1.812 & 1.848 & 1.852 & 1.853 \\
\hline $\mathrm{C}_{\mathrm{v} 1} \quad \mathrm{C}_{\mathrm{v} 2}$ & 1.344 & 1.390 & 1.344 & 1.386 & 1.391 & 1.385 & 1.343 & 1.388 & 1.387 & 1.386 \\
\hline $\mathrm{C}_{\mathrm{v} 2} \quad \mathrm{C}_{\mathrm{i} 1}$ & 1.473 & 1.426 & 1.474 & 1.423 & 1.429 & 1.440 & 1.476 & 1.432 & 1.437 & 1.440 \\
\hline \multirow[t]{2}{*}{$C_{i 1} \quad C_{p h 1}$} & 1.401 & 1.417 & 1.403 & 1.423 & 1.417 & 1.411 & 1.403 & 1.415 & 1.412 & 1.411 \\
\hline & 1.406 & 1.420 & 1.404 & 1.424 & 1.419 & 1.412 & 1.402 & 1.415 & 1.413 & 1.412 \\
\hline \multirow[t]{2}{*}{$\mathrm{C}_{\mathrm{ph} 1} \mathrm{C}_{\mathrm{ph} 2}$} & 1.385 & 1.373 & 1.386 & 1.369 & 1.375 & 1.380 & 1.389 & 1.378 & 1.381 & 1.381 \\
\hline & 1.389 & 1.376 & 1.387 & 1.370 & 1.375 & 1.380 & 1.389 & 1.379 & 1.381 & 1.382 \\
\hline \multirow[t]{2}{*}{$\mathrm{C}_{\mathrm{ph} 2} \quad \mathrm{C}_{\mathrm{i} 2}$} & 1.401 & 1.411 & 1.403 & 1.421 & 1.413 & 1.407 & 1.401 & 1.409 & 1.406 & 1.406 \\
\hline & 1.405 & 1.416 & 1.403 & 1.420 & 1.413 & 1.407 & 1.400 & 1.409 & 1.407 & 1.404 \\
\hline $\mathrm{C}_{\mathrm{i} 2} \quad \mathrm{C}_{\mathrm{e}}$ & 1.466 & 1.451 & 1.466 & 1.433 & 1.446 & 1.462 & 1.489 & 1.481 & 1.482 & 1.485 \\
\hline $\mathrm{C}_{\mathrm{e}} \quad \mathrm{C}_{\mathrm{e}^{\prime}}$ & 1.342 & 1.350 & 1.344 & 1.363 & 1.358 & 1.345 & 1.347 & 1.351 & 1.351 & 1.349 \\
\hline$C_{e^{\prime}} \quad C_{i 2^{\prime}}$ & 1.469 & 1.461 & 1.466 & 1.444 & 1.446 & 1.462 & 1.489 & 1.486 & 1.482 & 1.485 \\
\hline \multirow[t]{2}{*}{$\mathrm{C}_{\mathrm{i} 2^{\prime}} \quad \mathrm{C}_{\mathrm{ph} 2^{\prime}}$} & 1.401 & 1.402 & 1.403 & 1.409 & 1.413 & 1.407 & 1.401 & 1.402 & 1.407 & 1.406 \\
\hline & 1.403 & 1.405 & 1.403 & 1.409 & 1.413 & 1.407 & 1.400 & 1.400 & 1.407 & 1.404 \\
\hline \multirow[t]{2}{*}{$\mathrm{C}_{\mathrm{ph} 2^{\prime}} \quad \mathrm{C}_{\mathrm{ph} 1^{\prime}}$} & 1.389 & 1.387 & 1.386 & 1.381 & 1.375 & 1.380 & 1.389 & 1.388 & 1.381 & 1.381 \\
\hline & 1.391 & 1.390 & 1.387 & 1.381 & 1.375 & 1.380 & 1.389 & 1.387 & 1.381 & 1.381 \\
\hline \multirow[t]{2}{*}{$C_{p h 1^{\prime}} \quad C_{i 1^{\prime}}$} & 1.395 & 1.396 & 1.403 & 1.409 & 1.417 & 1.412 & 1.403 & 1.403 & 1.412 & 1.412 \\
\hline & 1.392 & 1.394 & 1.403 & 1.408 & 1.419 & 1.412 & 1.403 & 1.402 & 1.413 & 1.412 \\
\hline \multicolumn{3}{|l|}{$C_{i^{\prime}} \quad C_{v 2^{\prime}}$} & 1.474 & 1.464 & 1.429 & 1.429 & 1.441 & 1.474 & 1.437 & 1.440 \\
\hline \multicolumn{3}{|l|}{$\mathrm{C}_{\mathrm{v}^{\prime}{ }^{\prime}} \mathrm{C}_{\mathrm{v1}^{\prime}}$} & 1.344 & 1.350 & 1.391 & 1.391 & 1.343 & 1.344 & 1.387 & 1.385 \\
\hline \multicolumn{3}{|l|}{$\mathrm{C}_{\mathrm{vI}^{\prime}} \mathrm{Ru}$} & 1.981 & 1.966 & 1.877 & 1.883 & 1.983 & 1.979 & 1.882 & 1.883 \\
\hline
\end{tabular}

couplings of 7.15 and $3.12 \mathrm{G}$ to two different $I=1 / 2$ nuclei had to be included to obtain a satisfactory fit, and these are assigned to the $\alpha$ and $\beta$ vinyl protons, $\mathrm{Ru}-\mathrm{CH}$ and $\mathrm{RuCH}=\mathrm{CH}$. Calculated EPR parameters and average hyperfine splitting constants to ${ }^{31} \mathrm{P}$ and ${ }^{99 / 101} \mathrm{Ru}$ nuclei are listed in Table S7 of the SI and provide an overall good fit to the experimental ones. Their EPR parameters characterize these radical cations as metal perturbed organic paramagnetic species with a mainly ligand centered spin, just as it was found for similar oxidized styryl ruthenium complexes. ${ }^{10 \mathrm{c}, 11 \mathrm{a}, 12 \mathrm{~h}}$

Two further details are worth of mention here. First, the observation of identical hyperfine splitting constants to two $\left.\mathrm{RuCl}(\mathrm{CO}) \mathrm{P}^{i} \mathrm{Pr}_{2}\right)_{2}$ moieties in $\mathbf{R u ~ E 2}{ }^{\mathbf{0 +}}$ and $\mathbf{R u} \mathbf{Z 2 f i x}^{\circ+}$ and the reduction of the hyperfine splitting parameters by a factor of $\sim 1 / 2$ with respect to $\mathrm{Ru} \mathrm{E} 1^{\circ+}$ indicate complete spin delocalization within these systems and a symmetrical spin density distribution across the two styryl ruthenium subunits. Based on these results, both radical cations can therefore be assigned as belonging to Class III of mixed valent (MV) compounds on the EPR time scale of $\sim 10^{-8} \mathrm{~s}$. Second, due the rather low equilibrium constant of the comproportionation reaction (vide ante) $\mathbf{R u} \mathbf{E 2}^{\circ+}$ and $\mathbf{R u} \mathbf{Z 2 f i x}^{\bullet+}$ are in equilibrium with their dioxidized dications and the neutrals. Under any experimental conditions, the only signals detected were, however, those of the radical cations. This lets us conclude that the dications have a singlet ground state and that the excited triplet state is too high in energy to be populated to a detectable limit at $\mathrm{rt}$.

Aspects of Charge Delocalization of the Radical Cations. Vibrational spectroscopy is an ideal tool for probing intrinsic charge delocalization of MV systems on the short vibrational time scale. Utilization of metal-carbonyl stretches to these ends has ample precedence as shown by the elegant work particularly of Geiger ${ }^{13 a-c}$ and Kubiak ${ }^{13 d-g}$ and can, under favorable circumstances, provide accurate electron transfer rates and reveal the entanglement of bridge vibrations and solvent dynamics in electron transfer processes. The observation of a pattern of two $\mathrm{Ru}-\mathrm{CO}$ bands for $\mathbf{R u} \mathbf{E} 2^{\circ+}$ and for $\mathbf{R u ~ Z 2 f i x}{ }^{0+}$ with distinct $\mathrm{CO}$ bands different from those of the neutrals and the dications and the intensity gain for the vinyl $\mathrm{C}=\mathrm{C}$ bands indicate that the charge (electron hole) created during the first oxidation process is unevenly distributed over the two styryl ruthenium subunits. Partial charge localization is also indicated by quantum chemical calculations on the $\mathrm{PMe}_{3}$ model complexes $\mathbf{R u ~ E 2}{ }^{\mathrm{Meo+}}$ and $\mathbf{R u}$ $\mathrm{Z2fix}^{\mathrm{Me} \bullet+}$. Structure optimization with inclusion of the 
dichloromethane solvent within the polarizable continuum (PCM) model produced noncentrosymmetric structures where one styryl ruthenium subunit experiences only minor structural changes when compared to the neutral whereas the structural parameters of the other come close to those calculated for the respective dication. Structural changes on oxidation include a shortening of the $\mathrm{Ru}-\mathrm{C}_{\mathrm{v} 1}$ and the $\mathrm{C}_{\mathrm{v} 1}-\mathrm{C}_{\mathrm{i} 1}$ bonds, an elongation of the $\mathrm{C}_{\mathrm{v} 1}=\mathrm{C}_{\mathrm{v} 2}$ bond and a higher degree of quinoidal distortion of the attached phenylene ring at the primary oxidation site (see Table 9). We also observe a clear trend toward a planarization of the entire metal-organic $\pi$ system. Thus, the $\mathrm{C}_{\mathrm{ph} 2^{\prime}}-\mathrm{C}_{\mathrm{i} 2^{\prime}}-\mathrm{C}_{\mathrm{e}^{\prime}}=\mathrm{C}_{\mathrm{e}}$ and $\mathrm{C}_{\mathrm{ph} 1}-\mathrm{C}_{\mathrm{i} 1}-\mathrm{C}_{\mathrm{v} 2}=\mathrm{C}_{\mathrm{v} 1}$ dihedral of $\mathbf{R u ~ E 1} 1^{\mathrm{Me}}$ ( $\Phi$ and $\Phi^{\prime}$ in Scheme 5) change from 11.3 and $11.6^{\circ}$ to $0.2^{\circ}$ or $0.0^{\circ}$ upon oxidation. Similar trends are also seen in going from $\mathrm{Ru} E 2^{\mathrm{Me}}$ to $\mathrm{Ru} \mathrm{E} 2^{\mathrm{Meo+}}$ and to $\mathrm{Ru} \mathrm{E}_{2}{ }^{\mathrm{Me} 2+}$ with slightly lower torsions for the "oxidized" site. Owing to the more rigid cyclohexenyl backbone, hardly any conformational change is seen for the members of the $\mathbf{R u ~} \mathbf{Z} 2 \mathrm{fix}^{\mathbf{n}}{ }^{\mathbf{}}$ redox series.

This pattern is identical to the one observed on oxidation of purely organic stilbenes and finite phenylene vinylene oligomers. It has been shown that the predicted expense of the structural distortions and the number of phenylene vinylene units that are affected by oxidation (i.e., the conjugation length of the polaron) strongly depend on the quantum chemical approach and the functional used in the calculations. ${ }^{5 \mathrm{c}}$ The DFT with large admixture of HF exchange in the hybrid functional used here has been shown to perform well for mixed valent vinyl and similar alkynyl bridged diruthenium or diiron complexes. $^{8 \mathrm{~d}, 9 \mathrm{c}, 10 \mathrm{f}, 48}$ It is worth noting that symmetry breaking and charge localization occur only after the inclusion of the solvent while gas phase calculations inevitably led to inherently centrosymmetric structures. Similar results have been obtained for bridged bis(triarylamine)radical cations. ${ }^{8 \mathrm{~d}, 48 \mathrm{a}}$ It has long been known that the solvent environment exerts a strong influence on a mixed valent system and may tip the scale toward either a localized (valence trapped) or a delocalized (valence detrapped) electronic structure. ${ }^{58}$

The spin density plots in Figure 19 illustrate that the structural asymmetry of $\mathbf{R u ~ E 2}{ }^{\text {Meo+ }}$ and $\mathbf{R u ~ Z 2 f i x}{ }^{\text {Meo+ }}$ also carries over to their electronic structures. Moreover, the calculations correctly furnish a pattern of two $\mathrm{Ru}-\mathrm{CO}$ bands with overall $\mathrm{CO}$ band shifts close to the experimentally observed ones (Table 6). Complete spin delocalization is, however, observed on the slower EPR time scale, indicating that intramolecular electron transfer from the reduced styryl ruthenium subunit to the oxidized one occurs at a rate in between the EPR and IR time scales of $10^{-8}$ and $10^{-12} \mathrm{~s}$, respectively. ${ }^{10 c, 13 \mathrm{~b}}$ This adds the compounds to the growing list of "almost delocalized" mixed valent systems. ${ }^{59}$ For dications $\mathrm{Ru} \mathrm{E2}^{\mathrm{Me} 2+}$ and Ru Z2fix ${ }^{\mathrm{Me} 2+}$ the DFT calculated (M05/PCM) energy differences of singlet and triplet states are only small. In the case of $\mathrm{Ru} \mathrm{E2}^{\mathrm{Me2+}}$ the singlet is calculated to be at lower energy $(\Delta G=-0.07 \mathrm{eV})$, while for $\mathbf{R u ~ Z 2 f i x}{ }^{\mathrm{Me2}+}$ the triplet is calculated at slightly lower energy with $\Delta G$ of $0.03 \mathrm{eV}$.

The relevance of the two $\mathrm{Ru}-\mathrm{CO}$ band pattern reaches, however, further. Geiger et al. have shown that the relative $\mathrm{CO}$ band shifts of the intermediate radical cations provide a charge distribution parameter $\Delta \rho$ as a quantitative measure of ground state delocalization of a mixed valent system. ${ }^{13 a, 60}$ As by its definition (see Figure 20 and eq 8), the charge distribution parameter $\Delta \rho$ scales between 0.0 and 0.5. A $\Delta \rho$ of 0.0 indicates the limit of a valence localized system of Class I while a value of 0.5 denotes the other extreme of a Class III system with full
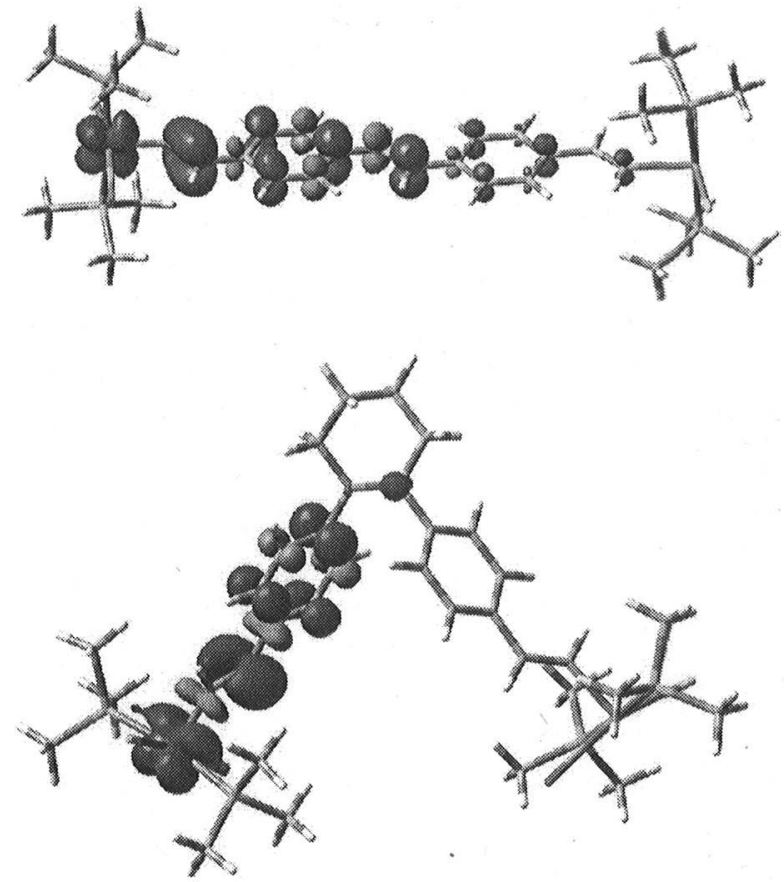

Figure 19. Spin density plots of $\mathbf{R u ~ E 2}{ }^{\circ+}$ (top) and $\mathbf{R u ~} \mathrm{Z2fix}^{\circ+}$ (bottom).

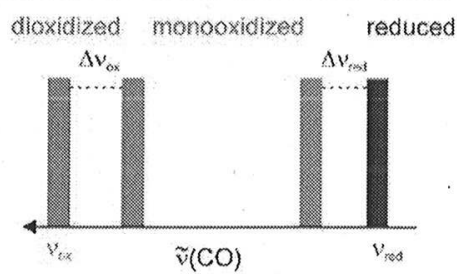

Figure 20. Definition of Geiger's charge delocalization parameter.

charge delocalization where the two redox active subunits are intrinsically equivalent. Class II systems occupy a position between these two extremes, and their position along this continuum can be determined from the $\Delta \rho$ value. $\mathrm{Ru}-\mathrm{CO}$ band shifts extracted from the nonlinear curve fitting procedure yields $\Delta \rho=0.19$ for $\mathbf{R u ~ E 2}{ }^{\circ+}$ and $\Delta \rho=0.09$ for $\mathbf{R u ~ Z 2 f i x}{ }^{\circ+}$. While the exact numbers may be somewhat compromised from remaining uncertainties associated with fitting procedures, it is nevertheless clear, that $\mathbf{R u ~ E} 2^{\bullet+}$ is much more delocalized than Ru Z2fix ${ }^{\text {e+ }}$. As has been pointed out on several occasions there is no direct relation between $\Delta E_{1 / 2}$ or $K_{c}$ and electronic coupling $^{37,61}$ despite many such notions in the literature. The small $\Delta E_{1 / 2}$ values of Ru E2 and Ru Z2fix merely reflect the relatively small thermodynamic stabilities of the radical cations with respect to the bordering neutrals and dications and are more affected by electrostatics than by the electronic coupling term. This is readily reconciled with the closer spatial proximity of the styryl ruthenium subunits in $\mathbf{R u} \mathbf{Z 2 f i x}{ }^{\circ+}$ compared to $\mathrm{Ru} \mathrm{E2}^{\circ+}$. When considering the small magnitude of the redox splitting, the degree of ground state delocalization is never theless astoundingly large for both isomers, and, in particular for $\mathrm{Ru} \mathrm{E2}^{\circ+}$. Thus, the 1,3 and 1,4 isomers of diethynylphe nylene bridged diruthenium complexes trans $[\{\mathrm{Cl}(\mathrm{dppe})$ $\left.\mathrm{Ru}\}_{2}\left(\mu \mathrm{C} \equiv \mathrm{C}-\mathrm{C}_{6} \mathrm{H}_{4}-\mathrm{C} \equiv \mathrm{C}-\right)\right]^{\bullet+}$ exhibit almost the same 
electronic coupling as $\mathbf{R u ~ Z 2} \mathrm{fix}^{\circ+}$ and $\mathbf{R u ~ E 2}{ }^{\circ+}(\Delta \rho=0.06$ and 0.17 ) at considerably larger $\Delta E_{1 / 2}$ values of 190 or $340 \mathrm{mV} .^{9 \mathrm{a}, 62}$ Sizable electronic interactions despite rather moderate $\Delta E_{1 / 2}$ and $K_{c}$ values are, however, not without precedence, $37,61 a, 63$ particularly in closely related stilbenyl and tolanyl bridged bis(triarylamines). ${ }^{16 c, 61 b, 64}$

$$
\Delta \rho=\Delta \nu_{\mathrm{ox}}+\Delta \nu_{\text {red }} /\left(2\left(\nu_{\mathrm{ox}}-\nu_{\text {red }}\right)\right)
$$

As was already mentioned in the introduction, the analysis of the intervalence charge transfer (IVCT, Class II) or charge resonance band (CR, Class III) provides in principle the most general access to the electronic coupling $V_{a b}$ of a mixed valent (MV) system. In the present case, however, we were not able to identify an IVCT band for the radical cations. As has been discussed in a previous section, the rather intense low energy transitions assume the character of $\pi \rightarrow \pi^{*}$ absorptions within a highly delocalized metal-organic $\pi$ chromophore and resemble those of the radical cations of purely organic oligo (phenylenevinylenes). Attempts to reproduce the experimental spectra by single determinant quantum chemical approaches provided no reliable results. Multideterminant CAS PT2 calculations are thus required but are beyond the scope of this paper. An estimate of $V_{a b}$ can, however, be derived from half the energy difference between the HOMO and HOMO-1 of the corresponding neutrals under the premises of Koopman's theorem. ${ }^{65}$ According to this procedure PBE0/PCM calculated $V_{a b}$ values are 0.302 and $0.169 \mathrm{eV}\left(2440\right.$ and $\left.1365 \mathrm{~cm}^{-1}\right)$ for Ru E2 ${ }^{\circ+}$ and Ru Z2fix ${ }^{\circ+}$, respectively. M05/PCM calculations give slightly larger $V_{a b}$ values of 0.378 and $0.209 \mathrm{eV} \mathrm{(3050 \text {and }}$ $1685 \mathrm{~cm}^{-1}$ ). While these numbers may be only qualitatively correct, they retrace the experimental trends in intrinsic electronic ground state delocalization.

Before closing, we draw an interesting analogy between triarylamine based MV systems and the styryl bridged diruthenium complexes of the present study. Both have in common, that the redox orbitals are not confined to the appended "redox sites", i. e. $\mathrm{Ar}_{2} \mathrm{~N}-\mathrm{C}_{6} \mathrm{H}_{4}$ and $\left(\mathrm{P}^{i} \mathrm{Pr}_{3}\right)_{2}(\mathrm{CO})$ $\mathrm{ClRu}$ but spread to a significant degree onto the nominal bridge. $V_{a b}$ parameters have been measured or calculated for several stilbenyl, arylethynyl, and arylene bridged bis (triarylamine) radical cations, with Barlow's vinyl, divinylphe nylene and divinylstilbenyl bridged radical cations $\mathbf{N} 2 \mathrm{Vi}^{{ }^{\circ+}}$ and N2 DVP $^{\circ+}$ of Chart 1 as the closest relatives of our present

\section{Chart 1}

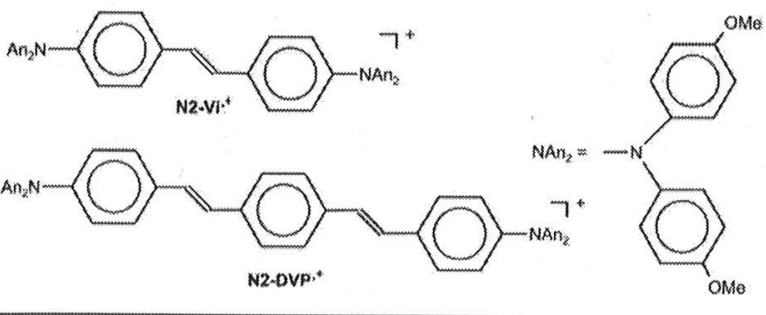

systems. $\mathbf{N} 2 \mathbf{V i}^{\bullet+}$ is intrinsically delocalized. ${ }^{61 \mathrm{~b}}$ An educated guess of the ground state delocalization parameter $\alpha\left(\alpha=V_{a b}\right)$ $\nu_{\text {max, IVCT }}$ ) of N2 $\mathrm{DVP}^{\circ+}$ in $\mathrm{CH}_{2} \mathrm{Cl}_{2}$ of $\sim 0.20-0.25$ is based on the experimental value of $\lambda$ and different estimates of the charge transfer distance $R_{a b}$ and of $V_{a b}{ }^{16 c}$ This value comes close to our $\Delta \rho$ parameter of 0.19 for $\mathbf{R u ~ E 2}{ }^{\circ+}$. (Note that both, $\Delta \rho$ and $\alpha$, measure the ground state delocalization of a MV system and scale between the limits of 0 for a valence localized MV system of Class I and 0.5 for a fully delocalized MV system of Class III. These parameters should thus be related). This suggests that the vinyl ruthenium $\{\mathrm{Ru}\}-\mathrm{CH}=$ $\mathrm{CH}-$ moiety comes close to the $\mathrm{An}_{2} \mathrm{~N}-\mathrm{C}_{6} \mathrm{H}_{4}-\mathrm{CH}=\mathrm{CH}-$ (An $=p$ anisyl, $\left.4 \mathrm{OMe}-\mathrm{C}_{6} \mathrm{H}_{4}\right)$ one with respect to its ability to form extended $\pi$ conjugated and electronically coupled mixed valent systems. It will thus be of interest to prepare and investigate triarylamine bridge-vinyl ruthenium conjugates that blend both motifs in one compound. Work along these lines is being detailed in a forthcoming paper. ${ }^{66}$

\section{CONCLUSIONS}

We are presenting here an in depth study of a monoruthenium stilbenyl and three distyrylethene bridged diruthenium com plexes that differ with respect to the configuration ( $E$ isomer Ru E2 versus $Z$ isomer $\mathbf{R u ~ Z 2 )}$ and the degree of conforma tional and configurational freedom (simple $Z$ isomer vs the backbone rigidified derivative $\mathbf{R u}$ E2fix where the central $\mathrm{C}=$ $\mathrm{C}$ double bond is incorporated into a rigid cyclohexene ring) at the central $\mathrm{C}=\mathrm{C}$ double bond. Attachment of vinyl ruthenium subunits has the effect of (i) increasing the conjugation length of the organic $\pi$ system in the same manner as adding an equivalent number of conjugated styryl units, (ii) decreasing the oxidation potential of the parent by about $1 \mathrm{~V}$ with respect to the parent phenylene vinylene, and (iii) increasing the number of easily accessible redox states by one per vinyl ruthenium subunit. "Substituent effects" on the position of the intense $\mathrm{UV} / \mathrm{vis}$ bands reveal that the simple $Z$ isomer maintains a large degree of $\pi$ conjugation along the unsaturated backbone while the effective conjugation is much more limited in backbone rigidified Ru Z2fix. This mirrors conformational trends in the solid state structures of these complexes. Dominant transitions in the UV/vis closely resemble those in the parent arenes as follows from their similar appearance and the results of TD DFT calculations. Voltammetric studies and accompanying digital simulations indicate that the dinuclear complexes $\mathbf{R u} \mathbf{E} \mathbf{2}$ and $\mathbf{R u} \mathbf{Z 2 f i x}$ are oxidized in two separate one electron steps with small differences of their half wave potentials $\Delta E_{1 / 2}$ (49 and $74 \mathrm{mV}$ ) and small comproportiona tion constants ( 7 and 12 , respectively). Oxidized $\mathbf{R u ~} \mathbf{Z 2}$ is configurationally unstable and readily converts to the $E$ isomer $\mathrm{Ru}$ E2 by an electron transfer catalyzed isomerization process. That isomerization is also triggered by weak oxidants even when the initial electron transfer is endergonic.

Oxidation of these complexes involves a predominantly bridge based HOMO which is unevenly distributed over the two styryl ruthenium subunits. Owing to specific "marker" bands in the infrared (IR) and near infrared (NIR) spectra, the radical cations could spectroscopically be identified as separate species in spite of the small $\Delta E_{1 / 2}$ and $K_{c}$ values. Phenomenologically, charge localization on predominantly one of the styryl ruthenium sites leads to a pattern of two $\mathrm{Ru}-\mathrm{CO}$ bands in the IR spectra of the mixed valent radical cations. This contrasts to full spin delocalization on the slower EPR time scale as is deduced from the analysis of the resolved hyperfine splittings for radical cations $\mathbf{R u ~ E 2}{ }^{\circ+}$ and $\mathbf{R u} \mathbf{Z 2 f i x}^{{ }^{\circ+}}$. Intramolecular electron transfer from the reduced to the oxidized styryl ruthenium site thus occurs at a rate in between the time scale inherent to the EPR $\left(\sim 10^{-8} \mathrm{~s}\right)$ and the IR experiment $\left(\sim 10^{-12} \mathrm{~s}\right)$. Analysis of the relative $\mathrm{CO}$ band shifts of the mixed valent radical cations with respect to the isovalent neutrals and dications allows us to quantify the ground state delocalization as $\sim 20 \%$ for $\mathbf{R u ~ E 2}^{\circ+}$ and $\sim 10 \%$ for less 
conjugated $\mathbf{R u ~ Z 2 f i x}{ }^{0+}$. These values are rather large when considering the small $\Delta E_{1 / 2}$ values observed in cyclic voltammetry. Quantum chemical calculations deliver a near quantitative description of the experimentally observed local ization/delocalization properties as is evident from the calculated structural changes and $\mathrm{CO}$ band shifts upon stepwise oxidation and EPR hyperfine coupling constants. The present work once more demonstrates the great utility of the $(\mathrm{CH}=$ $\mathrm{CH}) \mathrm{RuCl}(\mathrm{CO})\left(\mathrm{PR}_{3}\right)_{\mathrm{n}}$ "electrophore" in directly and quantita tively assessing the degree of ground state delocalization in mixed valent systems incorporating such units.

\section{ASSOCIATED CONTENT}

\section{Supporting Information}

Experimental details to general synthetic procedures, synthetic protocols for compound synthesis and characterization data tables pertaining to data collection and structure refinement for $\mathrm{X}$ ray crystallography, comparison of calculated and exper imental structure parameters and their changes upon oxidation, experimental and calculated electronic transitions for the parent alkynes and their ruthenium complexes, and calculated EPR parameters and hyperfine splittings for $\mathbf{R u ~ E 1}{ }^{\circ+}, \mathbf{R u} E 2^{\circ+}$ and Ru Z2fix ${ }^{\circ+}$. Figures showing packing diagrams, UV/vis spectra of the ethynyl substituted stilbenes, cyclic voltammograms of $\mathbf{R u ~ Z 2}$ and calculated electronic spectra of the ruthenium complexes, UV/vis/NIR spectra showing the electron transfer induced $Z \rightarrow E$ isomerization of $\mathbf{R u ~ Z 2}$, graphical representa tions of MOs involved in the optical electronic transitions of the ruthenium complexes and the potential dependence of the distribution between neutral, mono and dioxidized complexes. This material is available free of charge via the Internet at http://pubs.acs.org.

Crystallographic data have been deposited with the Cam bridge Structure Data Base as CCDC 885712 (Z2 Br), 885713 (Ru E1), 885714 (Z2 fixH), 885715 (Ru Z2fix), 885716 (Ru Z2), and 885717 (Ru E2) and can be obtained free of charge via www.ccdc.cam.ac.uk/conts/retrieving.html or from the Cambridge Crystallographic Data Centre, 12 Union Road, Cambridge CB2 1EZ, UK; fax (+44) 1223-336-033, or at deposit@ccdc.cam.ac.uk.

\section{AUTHOR INFORMATION}

Corresponding Author

rainer.winter@uni konstanz.de

Notes

The authors declare no competing financial interest.

\section{ACKNOWLEDGMENTS}

Financial support of this work by Deutsche Forschungsge meinschaft (grant Wi1272/72) and the Ministry of Education of the Czech Republic (grant COST LD11086) is gratefully acknowledged. We also wish to thank David Schweinfurth for the simulation of the EPR spectra in the frozen state.

\section{REFERENCES}

(1) (a) Rumi, M.; Ehrlich, J. E.; Heikal, A. H.; Perry, J. W.; Barlow, S.; $\mathrm{Hu}$, Z.; McCord Maughon, D.; Parker, T. C.; Röckel, H.; Thayumanvan, S.; Marder, S. R.; Beljonne, D.; Brédas, J. L. J. Am. Chem. Soc. 2000, 122, 9500. (b) Morel, Y.; Stephan, O.; Andraud, C.; Baldeck, P. L. Synth. Met. 2001, 124, 237. (c) Zhou, G.; Wang, X.; Wang, D.; Shao, Z.; Jiang, M. Appl. Opt. 2002, 41, 1120.
(2) (a) Waldeck, E. Chem. Rev. 1991, 91, 415. (b) Riedel, D.; Cranney, M.; Martin, M.; Guillory, R.; Dujardin, G.; Dubois, M.; Sonnet, P. J. Am. Chem. Soc. 2009, 131, 5414.

(3) (a) Bossert, J.; Daniel, C. Chem.-Eur. J. 2006, 12, 4835 (b) Polo, A. S.; Kayoko, M.; Frin, K. M.; de Toledo Patrocínio, A. O. Iha, N. Y. M. Coord. Chem. Rev. 2006, 250, 1669. (c) Patrocínio, A. O. T.; Iha, N. Y. M. Inorg. Chem. 2009, 47, 19851. (d) Coleman, A.; Draper, S. M.; Long, C.; Pryce, M. T. Organometallics 2007, 26, 4128. (e) Coleman, A.; Boyle, N. M.; Long, C.; Augulis, R.; Pugzlys, A.; van Loosdrecht, P. H. M.; Browne, W. R.; Feringa, B. L.; Ronayne, K. L.; Pryce, M. T. Dalton Trans. 2010, 39, 2201.

(4) (a) Heeger, A. J. Angew. Chem., Int. Ed. Engl. 2001, 40, 2591. (b) MacDiarmid, A. G. Angew. Chem., Int. Ed. Engl. 2001, 40, 2581.

(5) (a) Suzuki, H.; Koyano, K.; Shida, T.; Kira, A. Bull. Chem. Soc. Jpn. 1982, 55, 3690. (b) Tian, B.; Zerbi, G.; Müllen, K. J. Chem. Phys. 1991, 95, 3198. (c) Geskin, V. M.; Grozema, F. C.; Siebbeles, L. D. A.; Beljonne, D.; Brédas, J. L.; Cornil, J. J. Phys. Chem. B 2005, 109, 20237. (d) Lee, I. R.; Bañares, L.; Zewail, A. H. J. Am. Chem. Soc. 2008, 130, 6708 .

(6) (a) Hasegawa, T.; de Mayo, P. J. Chem. Soc., Chem. Commun. 1985, 1534. (b) Majima, T.; Tojo, S.; Ishida, A.; Takamuku, S. J. Org. Chem. 1996, 61, 7793. (c) Iwata, K.; Ozawa, R.; Hamaguchi, H. J. Phys. Chem. A 2002, 106, 3614. (d) Quenneville, J.; Martinez, T. J. J. Phys. Chem. A 2003, 107, 829. (e) Takeuchi, S.; Ruhman, S.; Tsuneda, T.; Chiba, M.; Taketsugu, T.; Tahara, T. Springer Ser. Chem. Phys. 2009, 92, 307. (f) Minezawa, N.; Gordon, M. S. J. Phys. Chem. A 2011, 115, 7901.

(7) (a) Lloveras, V.; Vidal Gancedo, J.; Ruiz Molina, D.; Figueira Duarte, T. M.; Nierengarten, J. F.; Veciana, J.; Rovira, C. Faraday Discuss. 2006, 131, 291. (b) Giacalone, F.; Segura, J. L.; Martin, N.; Guldi, D. M. J. Am. Chem. Soc. 2004, 126, 5340. (c) Giacalone, F.; Segura, J. L.; Martín, N.; Ramey, J.; Guldi, D. M. Chem.-Eur. J. 2005, $11,4819$.

(8) (a) Lambert, C.; Noell, G. J. Chem. Soc., Perkin Trans. 22002 , 2039. (b) Lambert, C.; Amthor, S.; Schelter, J. J. Phys. Chem. A 2004, 108, 6474. (c) Launay, J. P.; Coudret, C.; Hortholary, C. J. Phys. Chem B 2007, 111, 6788. (d) Kaupp, M.; Renz, M.; Parthey, M.; Stolte, M.; Wuerthner, F.; Lambert, C. Phys. Chem. Chem. Phys. $2011,13,16973$. (9) (a) Klein, A.; Lavastre, O.; Fiedler, J. Organometallics 2006, 25, 635. (b) Armitt, D. J.; Bruce, M. I.; Gaudio, M.; Zaitseva, N. N.; Skelton, B. W.; White, A. H.; Le Guennic, B.; Halet, J. F.; Fox, M. A.; Roberts, R. L.; Hartl, F.; Low, P. J. Dalton Trans. 2008, 6763. (c) Fox, M. A.; Le Guennic, B.; Roberts, R. L.; Bruce, D. A.; Yufit, D. S.; Howard, J. A. K.; Manca, G.; Halet, J. F.; Hartl, F.; Low, P. J. J. Am. Chem. Soc. 2011, 133, 18433.

(10) (a) Man, W. Y.; Xia, J. L.; Brown, N. J.; Farmer, J. D.; Yufit, D. S.; K. Howard, J. A.; Liu, S. H.; J. Low, P. Organometallics 201 1, 30, 1852. (b) Maurer, J.; Winter, R. F.; Sarkar, B.; Fiedler, J.; Záliš, S. Chem. Commun. 2004, 1900. (c) Maurer, J.; Sarkar, B.; Schwederski, B.; Kaim, W.; Winter, R. F.; Záliš, S. Organometallics 2006, 25, 3701. (d) Maurer, J.; Sarkar, B.; Kaim, W.; Winter, R. F.; Záliš, S. Chem.Eur. J. 2007, 13, 10257. (e) Mücke, P.; Zabel, M.; Edge, R; Collison, D.; Clément, S.; Záliš, S.; Winter, R. F. J. Organomet. Chem. 2011, 696, 3186. (f) Záliš, S.; Winter, R. F.; Kaim, W. Coord. Chem. Rev. 2010, 254, 1383. (g) Linseis, M.; Winter, R. F.; Sarkar, B.; Kaim, W.; Záliš, S. Organometallics 2008, 27, 3321.

(11) (a) Pevny, F.; Di Piazza, E.; Norel, L.; Drescher, M.; Winter, R. F.; Rigaut, S. Organometallics 2010, 29, 5912. (b) Wuttke, E.; Pevny, F.; Hervault, Y. M.; Norel, L.; Drescher, M.; Winter, R. F.; Rigaut, S. Inorg. Chem. 2012, 51, 1902.

(12) (a) Liu, S. H.; Chen, Y.; Wan, K. L.; Wen, T. B.; Zhou, Z.; Lo, M. F.; Williams, I. D.; Jia, G. Organometallics 2002, 21, 4984. (b) Liu, S. H.; Xia, H.; Wen, T. B.; Zhou, Z.; Jia, G. Organometallics 2003, 22, 737. (c) Xia, H.; Wen, T. B.; Hu, Q. Y.; Wang, X.; Chen, X.; Shek, L. Y.; Williams, I. D.; Wong, K. S.; Wong, G. K. L.; Jia, G. Organometallics 2005, 24, 562. (d) Yuan, P.; Wu, X. h.; Yu, G. a.; Du, D.; Liu, S. H. J. Organomet. Chem. 2007, 692, 3588. (e) Yuan, P.; Yin, J.; Yu, G. a.; Hu, Q.; Liu, S. H. Organometallics 2007, 26, 196. (f) Wu, X. H.; Jin, S.; Liang, J. H.; Yong, Z.; Yu, G. a.; Liu, S. H. Organometallics 2009, 28, 
2450. (g) Wu, X.; Weng, T.; Jin, S.; Liang, J.; Guo, R.; Yu, G. a.; Liu, S. H. J. Organomet. Chem. 2009, 694, 1877. (h) Maurer, J.; Linseis, M.; Sarkar, B.; Schwederski, B.; Niemeyer, M.; Kaim, W.; Záliš, S.; Anson, C.; Zabel, M.; Winter, R. F. J. Am. Chem. Soc. 2008, 130, 259. (i) Mücke, P.; Linseis, M.; Záliš, S.; Winter, R. F. Inorg. Chim. Acta 2011, 374, 36.

(13) (a) Atwood, C. G.; Geiger, W. E. J. Am. Chem. Soc. 2000, 122, 5477. (b) Atwood, C. G.; Geiger, W. E.; Rheingold, A. L. J. Am. Chem. Soc. 1993, 115, 5310. (c) Stoll, M. E.; Geiger, W. E. Organometallics 2004, 23, 5818. (d) Ito, T.; Hamaguchi, T.; Nagino, H.; Yamaguchi, T.; Kido, H.; Zavarine, I. S.; Richmond, T.; Washington, J.; Kubiak, C. P. J. Am. Chem. Soc. 1999, 121, 4625. (e) Yamaguchi, T.; Imai, N.; Ito, T.; Kubiak, C. P. Bull. Chem. Soc. Jpn. 2000, 73, 1205. (f) Lear, B. J.; Kubiak, C. P. Inorg. Chem. 2006, 45, 7041. (g) Glover, S. D.; Goeltz, J. C.; Lear, B. J.; Kubiak, C. P. Coord. Chem. Rev. 2010, 254, 331.

(14) Robin, M. B.; Day, P. Adv. Inorg. Chem. Radiochem. 1967, 10, 247.

(15) (a) Maurer, J.; Sarkar, B.; Zalis, S.; Winter, R. F. J. Solid State Electrochem. 2005, 9, 738. (b) Huang, D.; Streib, W. E.; Bollinger, J. C.; Caulton, K. G.; Winter, R. F.; Scheiring, T. J. Am. Chem. Soc. 1999, $121,8087$.

(16) (a) Bublitz, G. U.; Laidlaw, W. M.; Denning, R. G.; Boxer, S. G. J. Am. Chem. Soc. 1998, 120, 6068. (b) Oh, D.; Sano, M.; Boxer, S. G. J. Am. Chem. Soc. 1991, 113, 6880. (c) Barlow, S.; Risko, C.; Chung, S. J.; Tucker, N. M.; Coropceanu, V.; Jones, S. C.; Levi, Z.; Brédas, J. L.; Marder, S. R. J. Am. Chem. Soc. 2005, 127, 16900.

(17) Hill, A. F.; Shriver, D. E., Bruce, M. I., Eds.; Comprehensive Organometallic Chemistry III, Pergamon: Oxford, 1995; Vol. 7, 399.

(18) Lee, B. Y.; Bazan, G. C. J. Am. Chem. Soc. 2000, 122, 8577.

(19) Thorand, S.; Krause, N. J. Org. Chem. 1998, 63, 8551.

(20) Babudri, F.; Cardone, A.; Cassano, T.; Farinola, G. M.; Naso, F.; Tommasi, R. J. Organomet. Chem. 2008, 693, 2631.

(21) Rathore, R.; Lindeman, S. V.; Kumar, A. S.; Kochi, J. K. J. Am. Chem. Soc. 1998, 120, 6931.

(22) (a) Werner, H.; Esteruelas, M. A.; Otto, H. Organometallics 1986, S, 2295. (b) Jung, S.; Ilg, K.; Brandt, C. D.; Wolf, J.; Werner, H. Eur. J. Inorg. Chem. 2004, 469. (c) Maruyama, Y.; Yamamura, K. Sagawa, T.; Katayama, H.; Ozawa, F. Organometallics 2000, 19, 1308. (d) Kowalski, K.; Linseis, M.; Winter, R. F.; Zabel, M.; Zálišs, S.; Kelm, H.; Krüger, H. J.; Sarkar, B.; Kaim, W. Organometallics 2009, 28, 4196.

(23) (a) Monteath Robertson, J.; Woodward, I. Proc. R. Soc. London, Ser. A 1937, 162, 568. (b) Hoekstra, A.; Meertens, P.; Vos, A. Acta Crystallogr. 1975, B 31, 2813.

(24) Choi, S. H.; Bytheway, I.; Lin, Z.; Jia, G. Organometallics 1998, $17,3974$.

(25) (a) Hohlneicher, G.; Mueller, M.; Demmer, M.; Lex, J.; Penn, J. H.; Gan, L. X.; Loesel, P. D. J. Am. Chem. Soc. 1988, 110, 4483. (b) Philips, S. E. V.; Trotter, J. Acta Crystallogr. 1976, B32, 3098.

(26) Anet, F. A. L.; Haq, M. Z. J. Am. Chem. Soc. 1965, 87, 3147.

(27) (a) Jacquemin, D.; Wathelet, V. r.; Perpète, E. A.; Adamo, C. J. Chem. Theory Comput. 2009, S, 2420. (b) Fabian, J.; Diaz, L. A.; Seifert, G.; Niehaus, T. J. Mol. Struct. 2002, 594, 41. (c) Suzuki, T.; Mikami, N.; Ito, M. J. Phys. Chem. 1986, 90, 6431.

(28) Meić, Z.; Güsten, H. Spectrochim. Acta 1978, 34, 101.

(29) (a) Arenas, J. F.; Tocon, I. L.; Otero, J. C.; Marcos, J. I. J. Phys. Chem. 1995, 99, 11392. (b) Choi, C. H.; Kertesz, M. J. Phys. Chem. A 1997, 101, 3823.

(30) (a) Dyck, R. H.; McClure, D. S. J. Chem. Phys. 1962, 36, 2326. (b) Warshel, A. J. Phys. Chem. 1975, 62, 214. (c) Negri, F.; Orlandi, G. J. Mol. Struct. 2000, 521, 197.

(31) (a) Myers, A. B.; Mathies, R. A. J. Chem. Phys. 1984, 81, 1552. (b) Todd, D. C.; Fleming, G. R.; Jean, J. M. J. Chem. Phys. 1992, 97, 8915 .

(32) Beveridge, D. L.; Jaffé, H. H. J. Am. Chem. Soc. 1965, 87, 5340.

(33) Gierschner, J.; Mack, H.; Lüer, L.; Oelkrug, D. J. Chem. Phys. 2002, 116, 8596.

(34) Kubota, T.; Uno, B.; Matsuhisa, Y.; Miyazaki, H.; Kano, K. Chem. Pharm. Bull. 1983, 31, 373.

(35) Heinze, J. Angew. Chem., Int. Ed. Engl. 1984, 23, 831.
(36) (a) Myers, R. L.; Shain, I. Anal. Chem. 1969, 41, 980. (b) Richardson, D. E.; Taube, H. Inorg. Chem. 1981, 20, 1278.

(37) Hapiot, P.; Kispert, L. D.; Konovalov, V. Y.; Savéant, J. M. J. Am. Chem. Soc. 2001, 123, 6669.

(38) Flanagan, J. B.; Margel, S.; Bard, A. J.; Anson, F. C. J. Am. Chem. Soc. 1978, 100, 4248.

(39) Chung, M. C.; Gu, X.; Etzenhouser, B. A.; Spuches, A. M.; Rye, P. T.; Seetharaman, S. K.; Rose, D. J.; Zubieta, J.; Sponsler, M. B. Organometallics 2003, 22, 3485.

(40) Cassoux, P.; Dartiguepeyron, R.; Fabre, P. L.; De Monatuzon, D. Electrochim. Acta 1985, 30, 1485.

(41) Edwin, J.; Geiger, W. E. J. Am. Chem. Soc. 1990, 112, 7104.

(42) Pierce, D. T.; Geiger, W. E. J. Am. Chem. Soc. 1992, 114, 6063.

(43) (a) Nicholson, R. S.; Shain, I. Anal. Chem. 1964, 36, 706. (b) Hershberger, J. W.; Klingler, R. J.; Kochi, J. K. J. Am. Chem. Soc. 1983, 10S, 61. (c) Kukharenko, S. V.; Novikova, L. N.; Strelets, V. V.; Ustynyuk, N. A.; Yarmolenko, A. I. Russ. Chem. Bulletin 1994, 43, 1710. (d) Geiger, W. E.; Shaw, M. J.; Wünsch, M.; Barnes, C. E.; Foersterling, F. H. J. Am. Chem. Soc. 1997, 119, 2804.

(44) (a) Lewis, F. D.; Dykstra, R. E.; Gould, I. R.; Farid, S. J. Phys . Chem. 1988, 92, 7042. (b) Kuriyama, Y.; Arai, T.; Sakuragi, H.; Tokumaru, K. Chem. Phys. Lett. 1990, 173, 253. (c) Majima, T.; Tojo, S.; Ishida, A.; Takamuku, S. J. Phys. Chem. 1996, 100, 13615.

(45) Mevs, J. M.; Gennett, T.; Geiger, W. E. Organometallics 1991, $10,1229$.

(46) (a) Ward, T. A.; Levin, G.; Szwarc, M. J. Am. Chem. Soc. 1975 97, 258. (b) Sorensen, S.; Levin, G.; Szwarc, M. J. Am. Chem. Soc. 1975, 97, 2341. (c) Wang, H. C.; Levin, G.; Szwarc, M. J. Am. Chem. Soc. 1977, 99, 2642.

(47) Sherlock, S. J.; Boyd, D. C.; Moasser, B.; Gladfelter, W. L. Inorg. Chem. 1991, 20, 3626.

(48) (a) Renz, M.; Theilacker, K.; Lambert, C.; Kaupp, M. J. Am. Chem. Soc. 2009, 131, 16292. (b) Fox, M. A.; Roberts, R. L.; Baines, T. E.; Le Guennic, B.; Halet, J. F.; Hartl, F.; Yufit, D. S.; Albesa Jové, D.; Howard, J. A. K.; Low, P. J. J. Am. Chem. Soc. 2008, 130, 3566. (c) Costuas, K.; Cador, O.; Justaud, F.; Le Stang, S.; Paul, F.j Monari, A.; Evangelisti, S.; Toupet, L.; Lapinte, C.; Halet, J. F. Inorg. Chem. $2011,50,12601$.

(49) Suzuki, H.; Ogawa, K.; Shida, T.; Kira, A. Bull. Chem. Soc. Jpn. 1983, 56, 66.

(50) Deussen, M.; Bässler, H. Chem. Phys. 1992, 164, 247.

(51) Sakamoto, A.; Furukawa, Y.; Tasumi, M. J. Phys. Chem. 1994, 98, 4635 .

(52) Adams, C. J.; Connelly, N. G.; Rieger, P. H. Chem. Commun. 2001, 2458.

(53) Schenk, R.; Gregorius, H.; Müllen, K. Adv. Mater. 1991, 3, 492. (54) Voss, K. F.; Foster, C. M.; Smilowitz, L.; Mihailović, D.; Askari, S.; Srdanov, G.; Ni, Z.; Shi, S.; Heeger, A. J.; Wudl, F. Phys. Rev. B 1991, 43, 5109 .

(55) Choukroun, R.; Donnadieu, B.; Lorber, C.; Pellny, P. M.; Baumann, W.; Rosenthal, U. Chem.-Eur. J. 2000, 6, 4505.

(56) Baïtoul, M.; Wéry, J.; Buisson, J. P.; Arbuckle, G.; Shah, H.; Lefrant, S.; Hamdoume, M. Polymer 2000, 41, 6955.

(57) Winter, R. F.; Hornung, F. M. Organometallics 1999, 18, 4005.

(58) Chen, P.; Meyer, T. J. Chem. Rev. 1998, 98, 1439.

(59) Nelsen, S. F. Chem.-Eur. J. 2000, 6, 581.

(60) Stoll, M. E.; Lovelace, S. R.; Geiger, W. E.; Schimanke, H.; Hyla Kryspin, I.; Gleiter, R. J. Am. Chem. Soc. 1999, 121, 9343.

(61) (a) Kaim, W.; Klein, A.; Glöckle, M. Acc. Chem. Res. 2000, 33, 755. (b) Barlow, S.; Risko, C.; Coropceanu, V.; Tucker, N. M.; Jones, S. C.; Levi, Z.; Khrustalev, V. N.; Antipin, M. Y.; Kinnibrugh, T. L.; Timofeeva, T.; Marder, S. R.; Brédas, J. L. Chem. Commun. 2005, 764. (c) Barrière, F.; Camire, N.; Geiger, W. E.; Mueller Westerhoff, U. T.; Sanders, R. J. Am. Chem. Soc. 2002, 124, 7262. (d) D'Alessandro, D. M.; Keene, F. R. Dalton Trans. 2004, 3950. (e) D'Alessandro, D. M.; Keene, F. R. Chem. Soc. Rev. 2006, 3S, 424.

(62) (a) Colbert, M. C.; Lewis, J.; Long, N. J.; Raithby, P. R.; Younus, M.; White, A. J. P.; Williams, D. J.; Payne, N. N.; Yellowlees, L.; Beljonne, D.; Chawdhury, N.; Friend, R. H. J. Chem. Soc., Dalton Trans. 
1998, 3034. (b) Fox, M. A.; Farmer, J. D.; Roberts, R. L.; Humphrey, M. G.; Low, P. J. Organometallics 2009, 28, 5266.

(63) Gao, L. B.; Kan, J.; Fan, Y.; Zhang, L. Y.; Liu, S. H.; Chen, Z. N. Inorg. Chem. 2007, 46, 5651.

(64) Lambert, C.; Noell, G. J. Am. Chem. Soc. 1999, 121, 8434.

(65) (a) Newton, M. D. Chem. Rev. 1991, 91, 767. (b) Coropceanu, V.; Cornil, J.; da Silva Filho, D. A.; Olivier, Y.; Silbey, R.; Brédas, J. L. Chem. Rev. 2007, 107, 926.

(66) Polit, W.; Exner, T.; Wuttke, E.; Winter, R. F. Bioinorg. React. Mech. in the print. 